Published in final edited form as:

ACS Appl Mater Interfaces. 2020 March 04; 12(9): 10959-10972. doi:10.1021/acsami.9b21970.

\title{
Multi-Stimuli Responsive FRET Processes of Bifluorophoric AlEgens in an Amphiphilic Copolymer and Its Application to Cyanide Detection in Aqueous Media
}

\author{
Pham Quoc Nhien, \\ Department of Materials Science and Engineering, National Chiao Tung University, Hsinchu 300, \\ Taiwan \\ Wei-Lun Chou, \\ Department of Materials Science and Engineering, National Chiao Tung University, Hsinchu 300, \\ Taiwan \\ Tu Thi Kim Cuc, \\ Department of Materials Science and Engineering, National Chiao Tung University, Hsinchu 300, \\ Taiwan

\section{Trang Manh Khang,} \\ Department of Materials Science and Engineering, National Chiao Tung University, Hsinchu 300, \\ Taiwan \\ Chia-Hua Wu, \\ Department of Chemistry, University of Houston, Houston, Texas 77204, United States

\section{Natesan Thirumalaivasan,} \\ Department of Applied Chemistry, National Chiao Tung University, Hsinchu 300, Taiwan

\section{Bui Thi Buu Hue,} \\ Department of Chemistry, College of Natural Sciences, Can Tho University, Can Tho City 721337, \\ Vietnam
}

Judy I. Wu,

Department of Chemistry, University of Houston, Houston, Texas 77204, United States

\section{Shu-Pao Wu,}

Department of Applied Chemistry, National Chiao Tung University, Hsinchu 300, Taiwan

\section{Hong-Cheu Lin}

\footnotetext{
Corresponding Author: Hong-Cheu Lin, Phone: +886-3-5723803-55305; linhc@ mail.nctu.edu.tw.

Author Contributions

The manuscript was written through contributions of all authors. All authors have given approval to the final version of the manuscript.

The authors declare no competing financial interest.

ASSOCIATED CONTENT

Supporting Information

The Supporting Information is available free of charge at https://pubs.acs.org/doi/10.1021/acsami.9b21970.

Experimental details and additional data including ${ }^{1} \mathrm{H}, 13 \mathrm{C}$ NMR, HRMS, elemental analysis (EA), GPC, UV- vis, and fluorescence spectra (PDF)
} 
Department of Materials Science and Engineering and Center for Emergent Functional Matter Science, National Chiao Tung University, Hsinchu 300, Taiwan

\section{Abstract}

A novel amphiphilic aggregation-induced emission (AIE) copolymer, that is, poly(NIPAM-coTPE-SP), consisting of N-isopropylacrylamide (NIPAM) as a hydrophilic unit and a tetraphenylethylene-spiropyran monomer (TPE-SP) as a bifluorophoric unit is reported. Upon UV exposure, the close form of non-emissive spiropyran (SP) in poly(NIPAM-co-TPE-SP) can be photo-switched to the open form of emissive merocyanine (MC) in poly(NIPAM-co-TPE-MC) in an aqueous solution, leading to ratiometric fluorescence of AIEgens between green TPE and red MC emissions at 517 and $627 \mathrm{~nm}$, respectively, via Förster resonance energy transfer (FRET). Distinct FRET processes of poly(NIPAM-co-TPE-MC) can be observed under various UV and visible light irradiations, acid-base conditions, thermal treatments, and cyanide ion interactions, which are also confirmed by theoretical studies. The subtle perturbations of environmental factors, such as UV exposure, $\mathrm{pH}$ value, temperature, and cyanide ion, can be detected in aqueous media by distinct ratiometric fluorescence changes of the FRET behavior in the amphiphilic poly(NIPAM-co-TPE-MC). Moreover, the first FRET sensor polymer poly(NIPAM-co-TPEMC) based on dual AIEgens of TPE and MC units is developed to show a very high selectivity and sensitivity with a low detection limit $(\operatorname{LOD}=0.26 \mu \mathrm{M})$ toward the cyanide ion in water, which only contain an approximately $1 \%$ molar ratio of the bifluorophoric content and can be utilized in cellular bioimaging applications for cyanide detections.

\section{Graphical Abstract}

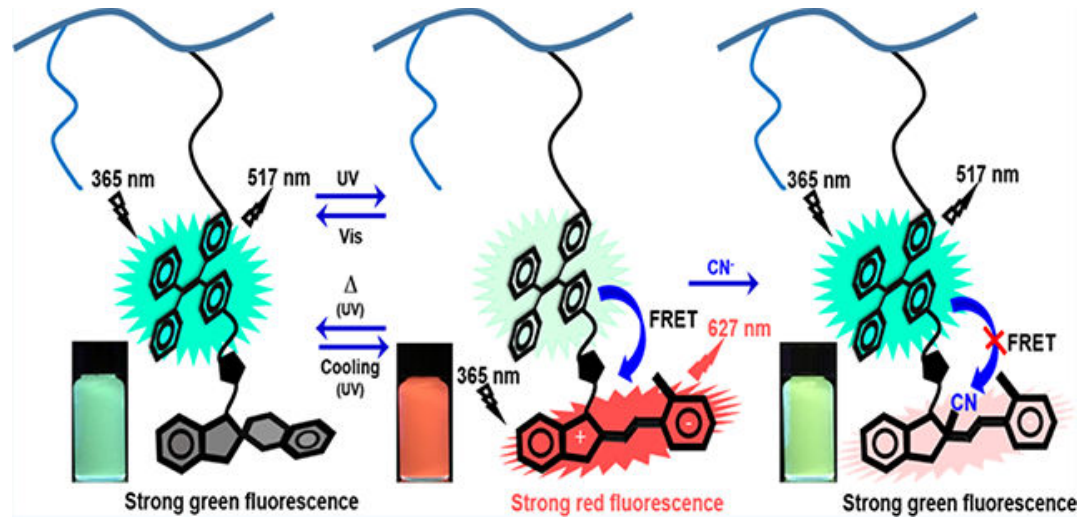

\section{Keywords}

aggregation-induced emission (AIE); cyanide; Förster resonance energy transfer (FRET); spiropyran; tetraphenylethylene

\section{INTRODUCTION}

As one of the most prevailing anions, cyanide $\left(\mathrm{CN}^{-}\right)$is a very dangerous and toxic anion, so the maximum allowable concentration of cyanide anion in drinking water is only $1.9 \mu \mathrm{M}$ based on the conclusion of the World Health Organization (WHO). ${ }^{1-4}$ Therefore, the 
developments of highly sensitive, selective, and effective sensor materials for the detection of $\mathrm{CN}^{-}$have drawn extensive attention of our eco-environments. So far, various fluorescence sensors for $\mathrm{CN}^{-}$recognition based on nucleophilic addition reaction into indolium moieties with poor aqueous solubilities ${ }^{5-10}$ and AIE properties ${ }^{11,12}$ have been presented. Besides, some water-soluble sensor polymers were also designed and reported to detect $\mathrm{CN}^{-}$in aqueous media. ${ }^{13,14}$ Especially, a water-soluble N-isopropylacrylamide (NIPAM)based copolymer containing another conjugated coumarin--spiropyran monomer was synthesized to be used for $\mathrm{CN}^{-}$detection in water. ${ }^{15}$

The concept of aggregation-induced emission (AIE) was firstly reported by Tang and coworkers in 2001 based on 1methyl-1,2,3,4,5-pentaphenylsilole molecule. ${ }^{16}$ As a well-known AIE luminogen, tetraphenylethylene (TPE) possesses the interesting AIE properties in the aggregation and solid states, ${ }^{17-19}$ so TPE-based materials have been broadly applied to various fluorescent bioprobes ${ }^{20-24}$ and chemosensors ${ }^{25-28}$ in aqueous (or semi-aqueous) solutions. In addition, some stimuliresponsive luminescent materials with mechanochromism, thermos-chromism, ${ }^{29}$ and photo-chromism ${ }^{30}$ for various applications have been reported in recent years. As a photochromic molecule, the close form of spiropyran (SP) can be reversibly photo-isomerized to the open form of merocyanine (MC), attributed to the cleavage of the C-O bond in the SP ring upon external stimuli. ${ }^{31}$ The reversible structural conversion of SP unit has been broadly employed in a wide range of applications, including optical switches, photo-patterning, biological systems, and chemosensors, ${ }^{32-38}$ where most SP and MC structures were utilized via their photochromic behavior. So far, just a few fluorophoric properties of SP and MC derivatives have been used for applications, ${ }^{39} \mathrm{pH}$ sensing ${ }^{40}$ especially for the sensor applications in aqueous solutions. ${ }^{41,42}$ With the advantages of Förster resonance energy transfer (FRET) in photoluminescence (PL) ${ }^{43-45}$ various bifluorophoric combinations of FRET processes between two energy donor and acceptor chromophores within a molecule ${ }^{46,47}$ (or supramolecule) ${ }^{48-50}$ and a mixture ${ }^{51}$ were reported. For instance, some FRET fluorescence probes of TPE donors with doxorubicin and rhodamine B derivatives ${ }^{52,53}$ or MC acceptors with azocarbazole ${ }^{54}$ and naphthalimide of $^{556}$ units have been presented. Moreover, the direct-coupling and conjugated connection of both TPE and SP chromophores without FRET behavior ${ }^{57,58}$ or with energy transfer ${ }^{59,60}$ have been designed and reported in recent years. To the best of our knowledge, no FRET behavior between TPE and SP (or MC) chromophores has been explored for the applications of sensor materials.

Though various bifluorophoric combinations of FRET donors and acceptors can be utilized as fluorescent bioprobes and chemosensors, the poor aqueous solubilities of bifluorophoric sensor materials need to be further improved to enhance their sensitivities in water. Hence, the mentioned FRET bifluorophoric monomer containing TPE and MC (or SP upon UV exposure) units is copolymerized with an NIPAM monomer to induce better water solubility for the detection of water-soluble analysts (for example, the cyanide detection in aqueous solutions). Besides the photo-responsive SP unit in the FRET bifluorophoric system, the introduction of poly(Nisopropyl-acrylamide) (PNIPAM) offers not only water solubility but also the temperature-responsive capability to this FRET luminescent copolymer, which also displays the upper critical solution temperature (UCST) or lower critical solution temperature (LCST) phase behavior in the aqueous solution. Herein, the dual TPE and MC 
AIEgens are integrated in the amphiphilic copolymer, that is, poly(NIPAM-co-TPE-MC), and its multi-stimuli responsive FRET processes were investigated by sensitive ratiometric fluorescence between bifluorophoric TPE and MC units, which also can be utilized for cyanide detection in water and bioimaging in living cells.

\section{EXPERIMENTAL SECTION}

\subsection{Materials}

All chemical reagents were purchased from commercial sources (TCI Japan, Sigma-Aldrich, Fisher Scientific, and J. T. Baker) and used directly as received without further purification.

The solvents used for reactions were purified/dried by the solvent purification system before using. For polymerization, the initiator AIBN $\left(2,2^{\prime}\right.$-azobis(2-methylpropionitrile)) and NIPAM monomer were purified by recrystallizing from methanol and $n$-hexane, respectively, prior to use. All reactions were carried out under nitrogen atmosphere and vacuum-line manipulations. Some reactants, catalysts, and organic solvents were used for reactions and purification of compounds, such as tetra-n-butylammonium bromide (TBAB), tosyl chloride (TsCl), disodium ethylenediaminetetraacetate dihydrate $\left(\mathrm{Na}_{2} \mathrm{EDTA} . \mathrm{H}_{2} \mathrm{O}\right.$ ), triethylamine (TEA), acetonitrile (ACN), ethanol (EtOH), dichloromethane (DCM), dimethylformamide (DMF), tetrahydrofuran (THF), diethyl ether $\left(\mathrm{Et}_{2} \mathrm{O}\right)$, ethyl acetate (EtOAc), hexane (Hex), and methanol (MeOH). The buffer solution (1 M MOPS, $\mathrm{pH}=7.0$ ) was prepared from 4-morpholinepropanesulfonic acid and sodium hydroxide solutions. All anion solutions $\left(\mathrm{CN}^{-}, \mathrm{F}^{-}, \mathrm{Cl}^{-}, \mathrm{Br}^{-}, \mathrm{I}^{-}, \mathrm{OH}^{-}, \mathrm{NO}^{--}, \mathrm{PF}^{-}, \mathrm{HCO}^{-}, \mathrm{HSO}^{-}, \mathrm{H} 2 \mathrm{PO}^{-}\right.$, $\mathrm{CH} 3 \mathrm{COO}^{-}, \mathrm{SO}^{2-}, \mathrm{HPO}_{4}^{2-}$, and $\mathrm{S}^{2-}$ ) were prepared in distilled water from their sodium, potassium, and ammonium salts.

\subsection{Characterizations and Measurements}

Nuclear magnetic resonance (NMR) spectra were recorded at room temperature on a Bruker Avance 300 and $500 \mathrm{MHz}$ instruments. High-resolution mass spectra were recorded on a Bruker-Impact HD mass spectrometer (ESI mode). Elemental analysis was performed using an Elementar Vario CUBE (CHN-OS Rapid, German). Polymer molecular weight and the polydispersity index were analyzed by gel permeation chromatography (Shodex GPC $\mathrm{KF}-805 \mathrm{~L}$ ) with tetrahydrofuran as the eluent at a flow rate of $1.0 \mathrm{~mL} / \mathrm{min}, 25^{\circ} \mathrm{C}$. Absorption spectra were recorded with an ultraviolet-visible near-infrared spectrophotometer (Lambda 950, PerkinElmer) between 200-800 nm. A fluorescence spectrophotometer (HITACHI F-4500) was used to measure the fluorescence properties of polymer.

\subsection{Cell Culture and Confocal Fluorescence Imaging}

The HeLa cells were grown in DMEM media supplemented with $10 \%(\mathrm{v} / \mathrm{v})$ FBS (fetal bovine serum) and penicillin/streptomycin $(100 \mu \mathrm{g} / \mathrm{mL})$ at $37^{\circ} \mathrm{C}$ in a $5 \% \mathrm{CO}_{2}$ incubator. The experiments to evaluate the sensing capability of polymers (close and open forms, i.e., poly(NIPAM-coTPE-SP) and poly(NIPAM-co-TPE-MC), respectively) for $\mathrm{CN}^{-}$in living cells were performed in $0.1 \mathrm{M}$ phosphate-buffered saline (PBS). The cells were treated with the close and open forms of polymers (10 $\mu \mathrm{M}$ based on SP and MC units) and incubated for $30 \mathrm{~min}$ at $37^{\circ} \mathrm{C}$. The culture medium was removed, and the treated cells were washed with 
0.1 M PBS $(2 \mathrm{ML} \times 3)$ before observation. Confocal fluorescence imaging of cells was performed with a Leica TCS SP5 X AOBS confocal fluorescence microscope (Germany), and a $63 \times$ oil-immersion objective lens was used. The excitation wavelength of $365 \mathrm{~nm}$ was applied for this experiment. Green and red emissions were collected at 500-550 and 600$650 \mathrm{~nm}$, respectively. Before and after the addition of $\mathrm{CN}^{-}(10 \mu \mathrm{M})$, the cells were incubated with the close and open forms of polymers (i.e., poly(NIPAM-co-TPE-SP) and poly(NIPAMco-TPE-MC), respectively) treated cells and their confocal fluorescence imaging changes were compared by different fluorescence colors from RGB channels.

\subsection{Cytotoxicity Assay}

The cytotoxicity of the close and open forms of polymers (i.e., poly(NIPAM-co-TPE-SP) and poly(NIPAMco-TPE-MC), respectively) were evaluated by MTT assay using HeLa cells. The cells were grown in a 96-well cell culture plate. Different amounts of polymers ( $0-25 \mu \mathrm{M}$ based on SP and MC units) were added in the culture medium and then kept at 37 ${ }^{\circ} \mathrm{C}$ with $5 \% \mathrm{CO}_{2}$ for $24 \mathrm{~h}$. The culture medium was added with $20 \mu \mathrm{L}$ methyl thiazolyl tetrazolium $(1 \mathrm{mg} / \mathrm{mL})$ and then kept at $37{ }^{\circ} \mathrm{C}$ with $5 \% \mathrm{CO}_{2}$ for $4 \mathrm{~h}$. Thereafter, the culture medium was removed, then $200 \mu \mathrm{L}$ DMSO was added, and finally, $20 \mu \mathrm{L}$ Sorenson's glycine buffer was also added to dissolve the yellow precipitates (formazan). Multiskan GO microplate reader was used to read the absorbance at $570 \mathrm{~nm}$. The cell viability was evaluated by the equation shown below.

cell viability $(\%)=($ mean absorbance of treatment group $) /($ mean absorbance of control group $)$

\subsection{Synthesis and Characterization}

The detailed information on the synthesis and characterization of compounds 1-8 and $\mathbf{S P}-\mathbf{N}_{\mathbf{3}}$ are shown in the Supporting information (section 1). The synthetic procedures of monomer TPE-SP and copolymer poly(NIPAM-coTPE-SP) are illustrated in Scheme 1.

2.5.1. Synthesis of Monomer TPE-SP-Compound $8(0.87 \mathrm{~g}, 1.50 \mathrm{mmol})$ and $\mathbf{S P}-\mathbf{N}_{\mathbf{3}}$ $(0.63 \mathrm{~g}, 1.65 \mathrm{mmol})$ were dissolved in dry DCM $(20 \mathrm{~mL})$. Then, $\left[\mathrm{Cu}\left(\mathrm{CH}_{3} \mathrm{CN}\right)_{4}\right] \mathrm{PF}_{6}(0.58 \mathrm{~g}$, $1.50 \mathrm{mmol}$ ) was added. The reaction mixture was stirred for $24 \mathrm{~h}$ at room temperature under nitrogen gas. Then, $100 \mathrm{~mL} \mathrm{Na}_{2}$ EDTA solution was added in the previous resulting mixture and extracted with $\mathrm{CH}_{2} \mathrm{Cl}_{2}(3 \times 50 \mathrm{~mL})$. The organic layer was dried over anhydrous $\mathrm{Na}_{2} \mathrm{SO}_{4}$ and evaporated to dryness. The crude product was further purified on silica gel using column chromatography with a mixed solvent $(\mathrm{DCM}: \mathrm{MeOH}=250: 1)$ as the eluent to gain the desired yellow solid product (bifluorophoric monomer TPE-SP). Yield: $1.24 \mathrm{~g}$ (87\%). ${ }^{1} \mathrm{H}$ NMR (300 MHz, CDCl $\left.{ }_{3}\right) \delta 8.00(\mathrm{dd}, \mathrm{J}=2.7 \mathrm{~Hz}, \mathrm{~J}=9 \mathrm{~Hz}, 1 \mathrm{H}), 7.93(\mathrm{~d}, \mathrm{~J}=2.7$ $\mathrm{Hz}, 1 \mathrm{H}), 7.50(\mathrm{~s}, 1 \mathrm{H}), 7.21-7.20(\mathrm{~m}, 1 \mathrm{H}), 7.12-7.00(\mathrm{~m}, 11 \mathrm{H}), 6.97-6.89(\mathrm{~m}, 5 \mathrm{H}), 6.73-$ $6.66(\mathrm{~m}, 4 \mathrm{H}), 6.60-6.54(\mathrm{~m}, 3 \mathrm{H}), 6.10(\mathrm{~s}, 1 \mathrm{H}), 5.55(\mathrm{t}, \mathrm{J}=1.5 \mathrm{~Hz}, 1 \mathrm{H}), 5.11-5.10(\mathrm{~m}, 2 \mathrm{H})$, 5.00-4.97 (m, 1H), 4.60-4.57 (m, 2H), $4.15(\mathrm{t}, \mathrm{J}=6.6 \mathrm{~Hz}, 2 \mathrm{H}), 3.85(\mathrm{t}, \mathrm{J}=6.6 \mathrm{~Hz}, 2 \mathrm{H})$, 3.75-3.52 (m, 2H), $1.95(\mathrm{~s}, 3 \mathrm{H}), 1.75-1.68(\mathrm{~m}, 4 \mathrm{H}), 1.47-1.43(\mathrm{~m}, 4 \mathrm{H}), 1.24(\mathrm{~s}, 3 \mathrm{H}), 1.05(\mathrm{~s}$, $3 \mathrm{H}) .{ }^{13} \mathrm{C} \mathrm{NMR}\left(125 \mathrm{MHz}, \mathrm{CDCl}_{3}\right) \delta 167.5,158.9,157.6,156.7,145.8,144.3,144.2,144.1$, $141.2,139.9,139.5,137.0,136.5,136.1,136.0,132.7,132.5,131.4,131.3,128.7,127.9$, $127.7,126.1,125.9,125.2,124.1,122.8,122.2,120.6,120.5,118.3,115.4,113.6,113.5$, 
106.4, 106.2, 67.6, 64.6, 61.7, 52.6, 48.8, 44.5, 30.3, 29.2, 28.5, 25.8, 25.7, 19.8, 18.3. HRMS $\left(\mathrm{ESI}^{+}\right)[\mathrm{M}+\mathrm{H}]^{+}$: calcd for $\mathrm{C}_{53} \mathrm{H}_{55} \mathrm{~N}_{6} \mathrm{O}_{4}$ 948.4331; found 948.4343. Elemental analysis: calcd for $\mathrm{C}_{53} \mathrm{H}_{55} \mathrm{~N}_{6} \mathrm{O}_{4}, \mathrm{C} 75.74, \mathrm{H} 6.06, \mathrm{~N} 7.39 \%$, found $\mathrm{C} 75.07, \mathrm{H} 6.35, \mathrm{~N}$ $7.42 \%$.

2.5.2. Synthesis of Poly(NIPAM-co-TPE-SP)—This copolymer was synthesized by free radical polymerization in the presence of thermal initiator AIBN with the hydrophilic monomer (NIPAM) and bifluorophoric monomer TPE-SP. First, monomers NIPAM (307 $\mathrm{mg}, 2.72 \mathrm{mmol})$ and TPE-SP $(25.8 \mathrm{mg}, 0.0272 \mathrm{mmol})$ were mixed with initiator AIBN (7 $\mathrm{mg}$ ) in dry THF. The mixture was degassed under the freeze-pump-thaw cycle three times and then heated up to $70{ }^{\circ} \mathrm{C}$ to react for 2 days. A few drops of $\mathrm{CH}_{3} \mathrm{OH}$ were added to terminate the polymerization. The resultant mixture was poured into cool ether and precipitated with ethyl ether several times and then filtrated. The desired copolymer was dried under vacuum to acquire copolymer poly(NIPAM-co-TPE-SP) as a slight orange solid. Yield: $200 \mathrm{mg}$. The composition of poly(NIPAM-co-TPE-SP) was determined by comparing the integral values of the band centered at $7.50 \mathrm{ppm}$ (one hydrogen of triazole group in monomer TPE-SP) and the band centered at 3.96 or $1.10 \mathrm{ppm}$ (one hydrogen CHor six hydrogens $\mathrm{CH}_{3}$ - of the isopropyl group in NIPAM, respectively) from ${ }^{1} \mathrm{H}$ NMR spectrum. According to the result of NMR spectrum (Figure S16), it indicates that the monomer ratio of NIPAM and TPE-SP (x:y) is 100:1. As shown in Figure S17a, the weight average molecular weight $\left(\mathrm{M}_{\mathrm{w}}\right)$ and polydispersity index $\left(\mathrm{PDI}=M_{W} / M_{n}\right)$ of polymer obtained by gel permeation chromatography (GPC) were 12,344 Da and 1.80, respectively.

\section{RESULTS AND DISCUSSION}

\subsection{Design and Synthesis of Monomer and Copolymer}

The bifluorophoric monomer TPE-SP was synthesized via "click" reaction (CuAAC) of alkyne 8 and $\mathbf{S P}-\mathbf{N}_{3}$ (see Scheme S1) in DCM with a $\left[\mathrm{Cu}\left(\mathrm{CH}_{3} \mathrm{CN}\right)_{4}\right] \mathrm{PF}_{6}$ catalyst under a mild condition. The detailed synthetic procedure of this monomer and $\mathbf{S P}-\mathbf{N}_{\mathbf{3}}$ are described in Scheme 1 and Schemes S1 and S2. The chemical structure of monomer TPE-SP is fully characterized by ${ }^{1} \mathrm{H}$ NMR, ${ }^{13} \mathrm{C}$ NMR, HRMS spectra, and EA results, which are shown in the Supporting information. With two hydrophobic fluorophores (TPE and SP) in the monomer TPE-SP, it shows poor water solubility, leading to the reduction of the fluorescence property as well as its applications in aqueous solutions. Therefore, a novel amphiphilic copolymer poly(NIPAM-co-TPE-SP) was designed and synthesized by the incorporation of TPE-SP into NIPAM through free radical copolymerization with 2,2' azobis(2-methylpropionitrile) (AIBN) as an initiator (Scheme 1), which has a molar ratio of NIPAM:TPE-SP $=100: 1$ with a molecular weight $\mathrm{M}_{\mathrm{w}}=12,344 \mathrm{Da}$ and PDI $=1.80$ (see Figures S16 and S17a). This polymer showed the typical properties of PNIPAM, including LCST and water solubility, as well as the AIE behavior of TPE units in the aggregation state and underwent the photo-isomerization of SP upon UV-vis irradiation. Hence, the FRET behavior between TPE and MC units in the aqueous solution of poly(NIPAM-coTPE-SP) after UV exposure can be observed and utilized in the sensor applications. Most interestingly, this FRET process in water induced changeable dual emissions, which were used to detect cyanide ion and applied for bioimaging in living cells. Various FRET 
phenomena were also confirmed by UV-vis and fluorescence spectra, as well as DFT computation in this report.

\subsection{AIE Properties}

In order to survey the AIE properties of this amphiphilic copolymer, the photoluminescence (PL) spectra of poly(NIPAM-co-TPE-SP) with the excitation wavelength of $365 \mathrm{~nm}$ are obtained in the THF/ $\mathrm{H}_{2} \mathrm{O}$ system with different water fractions (Figure 1a). We observed non-emissive PL behavior in pure and concentrated THF solutions of poly(NIPAM-coTPE-SP) due to the intramolecular rotations of TPE units in low water content solutions, which led to the consummation of the excited state energy non-radiatively. ${ }^{61}$ However, the $\mathrm{PL}$ emission intensity of polymer increased gradually in $\mathrm{THF} / \mathrm{H}_{2} \mathrm{O}$ solutions with water fractions $280 \%$ and reached the maximum emission at $100 \%$ water (Figure 1b) where the inset revealed the PL photo-images of polymer solutions with non-emission and green emission in pure THF and water, respectively. It suggests that the aggregation state of poly(NIPAM-co-TPE-SP) arose at high water contents $\left(\geq 80 \% \mathrm{H}_{2} \mathrm{O}\right)$ to turn on the AIE fluorescence due to the restriction of intramolecular motions of TPE units. ${ }^{18}$ Moreover, the average particle size of insoluble aggregates in the water solution is about $55.3 \mathrm{~nm}$, which was determined by dynamic light scattering (DLS) measurements (Figure S17b). These results indicate that the AIE behavior of the poly(NIPAM-co-TPE-SP) solution occurred over $80 \%$ water content and reached the largest AIE effect in the aqueous solution (100\% $\mathrm{H}_{2} \mathrm{O}$ ). Besides, the AIE effect of spiropyran and impact on FRET process in the aggregates of poly(NIPAM-co-TPE-MC) have been carried out and shown in Figure 1c,d (with the excitation wavelength of $365 \mathrm{~nm}$ ) where the spiropyran unit is opened by UV exposure to become MC moiety. In addition, we also proceeded the PL measurements of poly(NIPAMco-TPE-MC) with different $\mathrm{H}_{2} \mathrm{O}$ fractions in $\mathrm{THF} / \mathrm{H}_{2} \mathrm{O}$ solutions with the excitation at 554 $\mathrm{nm}$ of the best absorption of MC moieties, but the results reveal that the MC moieties exhibited the similar AIE behaviors in both excitation wavelengths of 554 and $365 \mathrm{~nm}$. Hence, the AIE effect on the open form of MC moiety in poly(NIPAM-co-TPE-MC) can be observed with stronger red emissions of $\mathrm{MC}$ at $627 \mathrm{~nm}$ at water contents higher than 50\% (see Figure 1d), which occurred at an earlier AIE stage than the TPE emission at $517 \mathrm{~nm}$ at water contents larger than 70\% (see Figure 1b). Moreover, the FRET contribution from the AIE donor of the TPE unit to the AIE acceptor of the MC unit can be observed in Figure 1c where the TPE emission of the AIE donor at $517 \mathrm{~nm}$ was reduced due to the FRET process to render its energy to the AIE acceptor of the MC unit in contrast to Figure 1a. Therefore, these amphiphilic copolymers, poly(NIPAM-co-TPE-SP) and poly(NIPAM-coTPE-MC), which exhibited the strongest AIE emissions in pure water, are further studied to demonstrate their novel applications.

\subsection{PL Properties and FRET Behavior}

The SP unit of copolymer could be gradually changed from the close form (SP) to the open form (MC) due to the cleavage of $\mathrm{C}$ (spiro)-O bond upon UV irradiation, ${ }^{38}$ which lets poly(NIPAM-co-TPE-SP) convert to poly(NIPAM-co-TPE-MC) (Scheme 1). In order to investigate the rate of the ring-opening process for SP unit by UV light and thus to control the bifluorophoric FRET behavior between TPE and SP (or MC) units in copolymer, the 
UV-vis and fluorescence spectra of the poly(NIPAM-co-TPE-SP) solution $(1 \mathrm{~g} / \mathrm{L})$ in deionized water (DI water) are studied and displayed in Figure 2a,b.

The absorption spectra of poly(NIPAM-co-TPE-SP) in water are illustrated upon UV irradiation at $365 \mathrm{~nm}$ (by a hand-held ultraviolet lamp) in Figure 2a, measured at different UV exposure time intervals with a $10 \mathrm{~s}$ time span (from 0 to $90 \mathrm{~s}$ ). We found that poly(NIPAM-co-TPE-SP) and poly(NIPAM-co-TPE-MC) could undergo reversible photoisomerization between SP and MC isomers after UV and visible light irradiation, respectively, where a new absorption peak at $554 \mathrm{~nm}$ attributed to the $\mathrm{MC}$ appeared and saturated at approximately 80-90 s of UV exposure time, and the color of polymer solutions changed from yellow in the original close form (SP) to purple in the open form (MC) (inset photo-images of Figure 2a). Moreover, the fluorescence color of polymer solutions showed more significant changes upon UV exposure. The PL spectra $\left(\lambda_{\mathrm{ex}}=365 \mathrm{~nm}\right)$ of poly(NIPAM-co-TPE-SP) in water are demonstrated in Figure $2 b$, with similar UV exposure processes to induce the open form of poly(NIPAM-co-TPEMC) at different UV exposure time intervals. The fluorescence intensities of MC unit at $627 \mathrm{~nm}$ were gradually enhanced and saturated at approximately 80-90 s of UV exposure time. However, due to the FRET process, the fluorescence intensity of TPE unit at $517 \mathrm{~nm}$ in Figure $2 \mathrm{~b}$ reduced gradually with increased UV exposure time and also saturated at approximately 80-90 s, which was matchable with the PL saturation of the open form (MC) at $627 \mathrm{~nm}$ in poly(NIPAM-co-TPE-MC). Finally, the PL emission color of polymer solutions changed from green in the original close form (SP) to red in the open form (MC) (inset photo-images of Figure $2 b$ ) where the initial green emission color (before UV exposure) was attributed to the major TPE at $517 \mathrm{~nm}$ and the final red emission (after UV exposure) was attributed to both contributions of enhanced MC red emission (at $627 \mathrm{~nm}$ ) and reduced TPE green emission (at $517 \mathrm{~nm}$ ). The FRET process of poly(NIPAM-co-TPE-MC) can be explained by the partial energy transfer from the TPE unit to the MC unit and was shown in Figure 2c. Hence, the PL emission at $517 \mathrm{~nm}$ of the TPE unit in poly(NIPAM-co-TPESP) was gradually dropped after UV exposure, owing to the FRET process of TPE energy transferred to MC units in the open form of poly(NIPAM-co-TPE-MC). Indeed, the MC absorption band of poly(NIPAM-co-TPE-MC) (absorption spectrum) is almost overlapped with the TPE emission band of poly(NIPAM-co-TPE-SP) (PL spectrum) in Figure 2d, leading to the energy absorption (energy acceptor) of the MC unit from the energy emission (energy donor) of the TPE unit, and thus to the enhancement of the MC emission at $627 \mathrm{~nm}$ and reduction of the TPE emission at $517 \mathrm{~nm}$, simultaneously. In addition, the time-resolved photoluminescence (TRPL) measurements of poly(NIPAM-co-TPE-SP) have been done to further confirm the FRET process between green TPE and red MC units, which is shown in Figure S18f. Regarding the close form in poly(NIPAM-co-TPE-SP), it shows a longer lifetime of $2.110 \mathrm{~ns}$ in the TPE emission (at $517 \mathrm{~nm}$ ) without FRET than that (1.228 ns) of the open form in poly(NIPAM-co-TPE-MC) with the FRET process. These results indicated that the novel red emission of poly(NIPAM-co-TPE-MC) in water was not only produced by the red MC emission (at $627 \mathrm{~nm}$ ) in its open form upon UV exposure but also further enhanced by the FRET process contributed from this specially designed bifluorophoric TPE and MC systems. 
To characterize the optical reversibility of visible light on poly(NIPAM-co-TPE-MC), the polymer solution was kept at room temperature under ambient light in a short time till no further intensity changes of UV-vis and PL spectra for the photo-isomerization process. We found that the naked-eye observation color of the solution changed from purple to pale yellow, and the green fluorescence was also turned back after $12 \mathrm{~h}$ (Figures S18a,b).

Moreover, Figure S18c shows the disappearance of the absorption peak at $554 \mathrm{~nm}$ under the ambient light for $12 \mathrm{~h}$ to verify the regain of the close form (SP), and the disappearance of the PL emission peak at $627 \mathrm{~nm}$ and the increased PL emission peak at $517 \mathrm{~nm}$ to reveal the recovery of the close form (SP) (Figure S18d). To investigate the photo-fatigue resistant property of poly(NIPAM-co-TPE-SP) under UV and visible light, an aqueous solution of this polymer was exposed under UV (365 nm) and visible light for 2 and $7 \mathrm{~min}$, respectively. We observed that poly(NIPAM-co-TPE-SP) underwent the photo-isomerization between $\mathrm{SP}$ and MC to enhance emission at $627 \mathrm{~nm}$ and to reduce emission at $517 \mathrm{~nm}$ where the ratios of PL intensities $\left(\mathrm{I}_{62} / \mathrm{I}_{517}\right)$ were slightly changed for 10 cycles (see Figure S18e), indicating that poly(NIPAM-co-TPE-SP) possesses a good photo-fatigue resistant property. These results indicated that the reversible UV and visible exposure processes to produce poly(NIPAM-coTPE-MC) and poly(NIPAM-co-TPE-SP), respectively, can be easily carried out under a handheld ultraviolet lamp (with 2 min of UV exposure time) and ambient light or a common LED lamp with white light at room temperature, promising possible practical applications for photo-switchable materials and smart devices in the future.

\section{4. pH Effects on FRET Behavior}

Interestingly, poly(NIPAM-co-TPE-SP) in its close form (non-emissive SP) showed strong green fluorescence originated from the TPE unit in Figure S19a where the fluorescence of poly(NIPAM-co-TPESP) and the non-emissive SP unit could not be influenced by the acidic and basic conditions, so the PL intensities of poly(NIPAM-co-TPE-SP) with different $\mathrm{pH}$ values were not affected (see in Figure S19b). However, the emission properties of poly(NIPAM-co-TPE-MC) in its open form (MC) were obviously changed in different $\mathrm{pH}$ values (Figure $3 \mathrm{a}$ and inset). As shown in Figure 3b, the MC emission of poly(NIPAMcoTPE-MC) at $627 \mathrm{~nm}$ decreased in the lower and higher ranges of $\mathrm{pH}$ values (i.e., $\mathrm{pH}=1$ 3 and 11-13) and possessed the strongest red emissions in near-neutralized conditions (i.e., $\mathrm{pH}=4-10)$, but the TPE emission of poly(NIPAM-co-TPE-MC) at $517 \mathrm{~nm}$ revealed the opposite way to have the lowest emission intensities in near-neutralized conditions (i.e., $\mathrm{pH}$ $=4-10$ ) and increased in the lower and higher ranges of $\mathrm{pH}$ values (i.e., $\mathrm{pH}=1-3$ and 1113). Therefore, the FRET process of TPE energy transferred to MC units in the open form of poly(NIPAM-coTPE-MC) was strongly dependent on the $\mathrm{pH}$ environment, and the best FRET process to induce the highest MC emissions in poly(NIPAM-co-TPE-MC) occurred at near-neutralized conditions (i.e., $\mathrm{pH}=4-10$ ). However, the TPE emissions of poly(NIPAM-co-TPE-SP) at $517 \mathrm{~nm}$ without the FRET process will not be changed at all $\mathrm{pH}$ values.

\subsection{Temperature Effects on FRET Behavior}

PNIPAM is a well-known water-soluble and thermo-responsive polymer. The lower critical solution temperature (LCST) of this polymer is typically approximately $32{ }^{\circ} \mathrm{C}$ in aqueous 
media. ${ }^{61}$ Herein, we determined LCST of poly(NIPAM-co-TPE-SP) in water by transmittance measurement. The LCST transition behavior of aqueous polymer solutions was studied through UV-vis measurements at 10 to $60^{\circ} \mathrm{C}$. We found that the transparent solution almost did not change at a low temperature (below $27^{\circ} \mathrm{C}$ ), which became turbid after increasing the temperature to $37^{\circ} \mathrm{C}$ (Figure S20a). Moreover, the transmittance was dramatically fallen to $50 \%$ of the initial value at $32{ }^{\circ} \mathrm{C}$, indicating that poly(NIPAM-coTPE-SP) still had temperature-responsive characteristics of PNIPAM with the LCST at 32 ${ }^{\circ} \mathrm{C}$. The reversible nature of poly(NIPAM-co-TPE-SP) solution was observed and shown in the inset of Figure S20a (top). Figure 4 and Figure S20b show the temperature effect on the fluorescence of poly(NIPAM-co-TPE-MC) in an aqueous solution by heating up to $60{ }^{\circ} \mathrm{C}$ and cooling to room temperature with UV exposure, respectively. The fluorescence intensities of poly(NIPAM-co-TPE-MC) in Figure 4a decreased at $627 \mathrm{~nm}$ and increased at $517 \mathrm{~nm}$ during the heating process $\left(20-60^{\circ} \mathrm{C}\right)$ under UV exposure due to the photoisomerization from the MC to the SP form and turn to poly(NIPAM-co-TPE-SP) by heating, where Figure $4 \mathrm{~b}$ reveals the relative changes of PL intensities at 627 and $517 \mathrm{~nm}$ for the MC and TPE units, respectively. Without UV exposure, poly(NIPAM-co-TPE-SP) maintained the temperature-independent close form and remained constant and strong green fluorescence from the TPE unit (see the bottom inset of Figure S20a), so the temperature changes could not affect the close form of poly(NIPAM-co-TPE-SP) at the range of 20-60 ${ }^{\circ} \mathrm{C}$. However, with UV exposure, the thermally reversible red emission of poly(NIPAM-coTPE-MC) gradually turned to green by heating over $40{ }^{\circ} \mathrm{C}$ and changed to green completely at approximately $55-60^{\circ} \mathrm{C}$ due to the isomerization of the close form (SP) and vice versa by cooling back to $20^{\circ} \mathrm{C}$ to recover the open form (MC) (Figure S20b) where the relative changes of PL intensities upon cooling is illustrated in the inset of Figure S20b. Hence, the temperature-dependent effect of thermally reversible fluorescence under UV exposure are also demonstrated in Figure S20c where the open form of poly(NIPAM-coTPE-MC) under UV exposure could be transformed to the close form of poly(NIPAM-co-TPE-SP) by heating up to $55-60{ }^{\circ} \mathrm{C}$ so as to eliminate the FRET process. According to these results, the temperature-dependent FRET process of poly(NIPAM-coTPE-MC) after UV exposure occurred due to the isomerization from the MC form to the SP form by heating, so the temperature effect was dominated over the UV exposure to induce the SP form of poly(NIPAM-co-TPE-SP) even with unfavorable UVexposure condition. However, the temperature-independent close form of poly(NIPAM-co-TPE-SP) indicates that the SP unit can only be opened by UV light rather than by heating.

\subsection{Ratiometric Fluorescent Probe for Cyanide Sensing}

Since poly(NIPAM-co-TPE-SP) was unable to react with $\mathrm{CN}^{-}$in its close form (SP) to detect the cyanide anion, no changes in its absorption and PL spectra were observed upon the addition of $\mathrm{CN}^{-}$(Figure S21). Herein, only poly(NIPAM-co-TPE-MC) as an amphiphilic FRET sensor material could react with $\mathrm{CN}^{-}$to enlarge and magnify the ratiometric fluorescence changes at two respective wavelengths of 517 and $627 \mathrm{~nm}$ to detect the cyanide ion by the relative ratios of their fluorescence intensities (i.e., $\mathrm{I}_{627} / \mathrm{I}_{517}$ ), which were much more distinct than their absorption changes by naked eye observation (Figures $\mathrm{S} 22$ and S23). According to the previous PL results in Figure 2b, the ratiometric fluorescence detection of $\mathrm{CN}^{-}$was carried out by continuous titrations with $\mathrm{CN}^{-}(0-110$ 
$\mu \mathrm{M})$ in a MOPS (3-(N-morpholino) propanesulfonic acid) buffer solution $(10 \mathrm{mM}, \mathrm{pH}=$ 7.0), and the diminished FRET process was induced by the reduction of MC emission at 627 $\mathrm{nm}$ (owing to the reaction of MC with $\mathrm{CN}^{-}$) and the recovery of TPE emission at $517 \mathrm{~nm}$ (Figure 5a). Besides, Figure S24c shows an excellent linear relationship between $\mathrm{I}_{62} / \mathrm{I}_{517}$ of poly(NIPAM-co-TPE-MC) and $\mathrm{CN}^{-}$concentration $(0-80 \mu \mathrm{M})$ where the PL emission also illustrated a significant color change from red to green during this $\mathrm{CN}^{-}$titration process (Figure S24a). Thus, the limit of detection (LOD) was calculated to be $0.26 \mu \mathrm{M}$ for $\mathrm{CN}^{-}$ based on the $3 \sigma / \mathrm{k}$ method from the fluorescence titration profile (Figure S24b,c), and the LOD of this work is much lower than most of the previous reports ${ }^{10,13-15}$ due to this excellent ratiometric PL results via the efficient FRET process. Moreover, the LOD of poly(NIPAMco-TPE-MC) is seven times lower than the maximum allowable $\mathrm{CN}^{-}$ concentration in drinking water by WHO $(1.9 \mu \mathrm{M}),{ }^{4}$ which provides a more sensitive FRET sensor material for the $\mathrm{CN}^{-}$detection in the aqueous solution. Since the $\mathrm{CN}^{-}$anion is a strong nucleophile group to attack the electron-deficient group easily, including the indolium $\left(-\mathrm{C}-\mathrm{C}=\mathrm{N}^{+}\right)$group, ${ }^{5-10,15} \mathrm{CN}^{-}$could react with carbon atom $\left(-\mathrm{C}=\mathrm{N}^{+}\right)$in $\mathrm{MC}$ moieties of poly(NIPAM-co-TPE-MC) to form an MC-CN system via nucleophilic addition, resulting in the interruption of $\mathrm{MC} \pi$ conjugation $^{10}$ to block the FRET process (see Figure $5 \mathrm{~b}$ ). Moreover, as shown in Figure S18f, the longer lifetime of poly(NIPAM-co-TPE-MC) + CN - in the reacted open form with $\mathrm{CN}^{-}(2.109 \mathrm{~ns})$ demonstrated the shutdown of FRET to regain the donor energy in the green TPE emission. Therefore, the FRET fluorescence of the $\mathrm{MC}$ unit was gradually quenched at $627 \mathrm{~nm}$ due to the reaction of $\mathrm{CN}^{-}$with $\mathrm{MC}$ to recover TPE emission at $517 \mathrm{~nm}$.

To examine the selectivity of this FRET sensor polymer toward $\mathrm{CN}^{-}$over other anions, the PL spectra of poly(NIPAMco-TPE-MC) in the MOPS buffer solution were recorded in the presence of respective analytes $(200 \mu \mathrm{M})$, including $\mathrm{F}^{-}, \mathrm{Cl}^{-}, \mathrm{Br}-$, I-, OH-, NO3-, PF6-, $\mathrm{HCO} 3-$, $\mathrm{HSO} 4-, \mathrm{H} 2 \mathrm{PO} 4-, \mathrm{CH}_{3} \mathrm{COO}^{-}\left(\mathrm{AcO}^{-}\right), \mathrm{SO}_{4}{ }^{2-}, \mathrm{HPO}_{4}{ }^{2-}, \mathrm{S}^{2-}$, GSH, and L-Cys. Among these analytes, $\mathrm{CN}^{-}$revealed the best contrast in their PL spectra and the most obvious emission color change from red to green (see Figure $5 \mathrm{c}$ and inset in Figure 5d) due to the largest elimination of its FRET process. The largest reduction of $I_{627} / I_{517}$ with an eight-fold smaller value for $\mathrm{CN}^{-}$was also observed in Figure 5d. These results verify that poly(NIPAM-co-TPE-MC) as a highly sensitive and selective FRET sensor toward $\mathrm{CN}^{-}$in water can be utilized for the detection applications in environmental and biological systems.

\subsection{Theoretical Calculations}

To better understand the FRET processes of poly(NIPAM-co-TPE-MC), we carried out DFT calculations of TPE-SP, TPE-MC, and TPE-MC- $\mathbf{C N}^{-}$using time-dependent density functional theory (TD-DFT) at IEF-PCM-B3LYP/6-31G(d) in water (see Table S1 and Figure 6). All computations were performed using the Gaussian 16 program. The optimized structures of TPE-SP and TPE-MC in their respective close and open forms revealed an approximately $1.3 \mathrm{~nm}$ central-to-central distance between the TPE to SP or MC centers (Figure 6a and Figure S25) and falls within the range of donor-acceptor distance (1-10 nm) required for the FRET process. ${ }^{44}$ The absorption wavelengths for TPE-SP, TPE-MC, and TPE-MC-CN ${ }^{-}$are within the range of 360-380 nm (Table S1), but an extra prominent peak is found for TPE-MC at $514 \mathrm{~nm}$ (close to TPE emission at $517 \mathrm{~nm}$, based on fluorescence 
spectra, see Figure $2 b$ ), suggesting a possible FRET process. The molecular orbital diagrams for TPE-SP, TPE-MC, and TPEMC-CN ${ }^{-}$are shown in Figure 6b-d. In TPE-SP, two absorptions occur at $359 \mathrm{~nm}$ (Figure 6b), a strong HOMO $\rightarrow$ LUMO+2 transition (oscillator strength $f=0.51$ ) corresponds to excitation on the TPE fragment, and a weaker HOMO-2 $\rightarrow$ LUMO transition ( $f=0.15$ ) corresponds to excitation on the SP fragment. In TPE-MC, the same absorptions occur at 360 and $361 \mathrm{~nm}$ (Figure 6c), and a strong absorption at $514 \mathrm{~nm}$, corresponding to HOMO- $\rightarrow$ LUMO transition in the MC motif $(f=0.77)$, indicates energy transfer from the TPE to the MC units. In TPE-SP, the SP unit adopts a close form and absorption for the HOMO-1 $\rightarrow$ LUMO transition is weak due to limited orbital overlap (absorption at $435 \mathrm{~nm}(f=0.01)$ ), leading to the absence of energy transfer (Figure 6b). In TPEMC-CN ${ }^{-}$, the MC unit reacted with $\mathrm{CN}^{-}$raises the energy of the LUMO orbital (from -2.92 to $-1.71 \mathrm{eV}$ ) (Figure $6 \mathrm{c}, \mathrm{d}$ ), resulting in a larger HOMO $\rightarrow$ LUMO gap of $0.7 \mathrm{eV}$ for TPEMC-CN ${ }^{-}(3.4 \mathrm{eV})$, a shorter absorption wavelength of $379 \mathrm{~nm}$ for HOMO $\rightarrow$ LUMO transition, and thus a shutdown of the FRET process.

The differences in the FRET behavior of TPE-MC at $\mathrm{pH}=1$ and $\mathrm{pH}=13$ (see the PL spectra in Figure 3a) can be explained by the changes in the orbital energies of the MC unit. The computational results in Figure 7a,b suggest that in the acidic media, a proton resides in between the oxygen atom attached to the TPE unit and the oxygen atom at the nitrophenolate in the MC unit (Figure 7a), and in the basic media, the alpha position neighboring the positively charged carbon is deprotonated (Figure 7b). The computed relative energies of different protonated/deprotonated forms are included in the Supporting Information (Figure S26 and Table S2). Both protonation and deprotonation widen the HOMO-LUMO gaps (to 3.2 and $3.4 \mathrm{eV}$, respectively, Figure 7c,d) and reduce the absorption wavelength (to 437 and $377 \mathrm{~nm}$, respectively, Table S1) of TPE-MC to a range where the FRET process becomes inaccessible.

\subsection{Cell Culture and Confocal Fluorescence Imaging of Polymers in Living Cells}

With dual fluorescence emissions, poly(NIPAM-co-TPE-SP) and poly(NIPAM-coTPEMC) could be utilized for cellular imaging on HeLa cells by a confocal fluorescence microscope. As shown in Figure 8, without $\mathrm{CN}^{-}$, we observed strong green fluorescence emissions at channels $\mathrm{f}-\mathrm{j}$ and strong red emissions at channels $\mathrm{p}-\mathrm{t}$ for close and open forms, respectively. Moreover, the overlay of TPE green or MC red emissions with the blue emission of DAPI revealed that poly(NIPAM-co-TPE-SP) and poly(NIPAM-coTPE-MC) were mostly localized in the cytoplasm over the nucleus of HeLa cells without and with $\mathrm{CN}^{-}$ treatments (Figures $8 \mathrm{j}, \mathrm{t}$ and $8 \mathrm{o}, \mathrm{y}$, respectively). Upon addition of $\mathrm{CN}^{-}(10 \mu \mathrm{M})$ to the close form treated cells, no conspicuous changes were obtained in the green fluorescence channel (Figure $8 \mathrm{~h}, \mathrm{~m}$ ), as well as no obvious changes in the overlay images (Figure $8 \mathrm{j}, \mathrm{o}$ ). However, the cells incubated with the open form exhibited the guest selectivity with $\mathrm{CN}^{-}$by enhanced green fluorescence (Figure 8r,w) and quenching of the red emission (Figure 8s, $\mathrm{x}$ ) and thus induced significant changes in the overlay images (Figure 8t,y) after the treatment of $\mathrm{CN}^{-}$ $(10 \mu \mathrm{M})$. These results indicate that poly(NIPAM-co-TPE-MC) could be particularly used for the bioimaging of the cyanide detection in living cells. In addition, the cytotoxicities of close and open forms were also evaluated by a standard MTT (methyl thiazolyl tetrazolium) assay using HeLa cells. The cells were grown in a 96-well cell culture plate, and different 
amounts of polymers ( $0-25 \mu \mathrm{M}$ based on SP and MC) were added in the medium and then kept at $37{ }^{\circ} \mathrm{C}$ with $5 \% \mathrm{CO}_{2}$ for $24 \mathrm{~h}$. The medium was added $20 \mu \mathrm{L}$ methyl thiazolyl tetrazolium $(1 \mathrm{mg} / \mathrm{mL})$ and then kept at $37{ }^{\circ} \mathrm{C}$ with $5 \% \mathrm{CO}_{2}$ for $4 \mathrm{~h}$. As shown in Figure $\mathrm{S} 27$, the cell viabilities are higher than $85 \%$ when the cells were treated with $25 \mu \mathrm{M}$ fluorophores for $24 \mathrm{~h}$, which demonstrates that both close and open forms of respective poly(NIPAM-co-TPE-SP) and poly(NIPAM-co-TPE-MC) had low cytotoxicities.

\section{CONCLUSIONS}

In summary, we synthesized an amphiphilic polymer poly(NIPAM-co-TPE-SP) and developed a novel FRET sensor material, poly(NIPAM-co-TPE-MC), based on the photoisomerization of SP and MC moieties under UV irradiation. Various FRET processes of this polymer were observed by UV- vis and PL spectra under UV and visible light, $\mathrm{pH}$ conditions, thermal treatments, and the interaction of $\mathrm{CN}^{-}$, which were further verified by DFT calculations. The FRET process of poly(NIPAM-co-TPE-MC) is proven to be $\mathrm{pH}$ and temperature-dependent, whereas poly(NIPAM-co-TPE-SP) maintained the strong green emission of TPE in different $\mathrm{pH}$ values and temperatures by the lack of FRET phenomena. Owing to the useful FRET behavior, poly(NIPAM-co-TPE-MC) could be utilized for detecting $\mathrm{CN}^{-}$by distinct ratiometric fluorescence changes with a very high selectivity and sensitivity $(\mathrm{LOD}=0.26 \mu \mathrm{M})$ in water. In addition, due to the good biocompatibility of poly(NIPAM-co-TPE-MC), this novel FRET sensor could be utilized for cellular imaging and $\mathrm{CN}^{-}$detection in living cells. Finally, the amplification of detection signals by ratiometric PL designs through FRET processes between TPE and MC AIEgens in poly(NIPAM-co-TPE-MC) might facilitate many promising sensor applications for chemical, environmental, and biological detections in aqueous media.

\section{Supplementary Material}

Refer to Web version on PubMed Central for supplementary material.

\section{ACKNOWLEDGMENTS}

The authors are grateful for the funding from the Ministry of Science and Technology, Taiwan, ROC. This work is supported by Ministry of Science and Technology, Taiwan (grant no. MOST106-2113-M-009-012-MY3, MOST107-2221-E-009043-MY2, and MOST108-3017-F-009-004) and the Center for Emergent Functional Matter Science of National Chiao Tung University from The Featured Areas Research Center Program within the framework of the Higher Education Sprout Project by the Ministry of Education (MOE) in Taiwan. J.I.W. thanks the National Science Foundation (CHE-1751370) and the National Institute of General Medical Sciences (NIGMS) of the National Institute of Health (R35GM133548) for grant support, as well as computational resources provided by the uHPC cluster, managed by the University of Houston and acquired through support from the NSF (MRI-1531814).

\section{REFERENCES}

(1). Kulig KW; Ballantyne B Cyanide Toxicity; US Department of Health \& Human Services, Public Health Service, Agency for Toxic Substances and Disease Registry, 1991.

(2). Wang F; Wang L; Chen X; Yoon J Recent Progress in the Development of Fluorometric and Colorimetric Chemosensors for Detection of Cyanide Ions. Chem. Soc. Rev. 2014, 43, 4312 4324. [PubMed: 24668230]

(3). Gale PA; Caltagirone C Anion Sensing by Small Molecules and Molecular Ensembles. Chem. Soc. Rev. 2015, 44, 4212-4227. [PubMed: 24975326] 
(4). World Health Organization Guidelines for Drinking-Water Quality; World Health Organization: Geneva, Switzerland, 2008.

(5). Yang L; Li X; Qu Y; Qu W; Zhang X; Hang Y; Ågren H; Hua J Red Turn-on Fluorescent Phenazine-Greenine Chemodosimeters for Cyanide Anion in Aqueous Solution and Its Application for Cell Imaging. Sens. Actuators, B 2014, 203, 833-847.

(6). Shiraishi Y; Nakamura M; Yamamoto K; Hirai T Rapid, Selective, and Sensitive Fluorometric Detection of Cyanide Anions in Aqueous Media by Greenine Dyes with Indolium-Coumarin Linkages. Chem. Commun. 2014, 50, 11583-11586.

(7). Li J; Qi X; Wei W; Liu Y; Xu X; Lin Q; Dong WA “DonorTwo-Acceptor” Sensor for Cyanide Detection in Aqueous Solution. Sens. Actuators, B 2015, 220, 986-991.

(8). Promchat A; Rashatasakhon P; Sukwattanasinitt M A Novel Indolium Salt as a Highly Sensitive and Selective Fluorescent Sensor for Cyanide Detection in Water. J. Hazard. Mater. 2017, 329, 255-261. [PubMed: 28183014]

(9). Yu Y; Shu T; Yu B; Deng Y; Fu C; Gao Y; Dong C; Ruan Y A Novel Turn-on Fluorescent Probe for Cyanide Detection in Aqueous Media Based on a BODIPY-Hemigreenine Conjugate. Sens. Actuators, B 2018, 255, 3170-3178.

(10). Rao PG; Saritha B; Rao TS Highly Selective Reaction Based Colorimetric and fluorometric Chemosensors for Cyanide Detection via ICT off in Aqueous Solution. J. Photochem. Photobiol., A 2019, 372, 177-185.

(11). Fang H; Cai G; Hu Y; Zhang J A Tetraphenylethylene-based Acylhydrazone Gel for Selective Luminescence Sensing. Chem. Commun. 2018, 54, 3045-3048.

(12). Zhang Y; Li D; Li Y; Yu J Solvatochromic AIE Luminogens as Supersensitive Water Detectors in Organic Solvents and Highly Efficient Cyanide Chemosensors in Water. Chem. Sci. 2014, 5, 2710-2716.

(13). Wan H; Gu P; Zhou F; Wang H; Jiang J; Chen D; Xu Q; Lu J Polyacrylic Esters with a "One-IsEnough" Effect and Investigation of Their AIEE Behaviors and Cyanide Detection in Aqueous Solution. Polym. Chem. 2018, 9, 3893-3899.

(14). Trigo-Lopez M; Munoz A; Mendía A; Ibeas S; Serna F; García FC; García JM PalladiumContaining Polymers as Hybrid Sensory Materials (Water-Soluble Polymers, Films and Smart Textiles) for the Colorimetric Detection of Cyanide in Aqueous and Gas Phases. Sens. Actuators, B 2018, 255, 2750-2755.

(15). Shiraishi Y; Sumiya S; Manabe K; Hirai T Thermoresponsive Copolymer Containing a Coumarin-Spiropyran Conjugate: Reusable Fluorescent Sensor for Cyanide Anion Detection in Water. ACS Appl. Mater. Interfaces 2011, 3, 4649-4656. [PubMed: 22043965]

(16). Luo J; Xie Z; Lam JWY; Cheng L; Chen H; Qiu C; Kwok HS; Zhan X; Liu Y; Zhu D; Tang BZ Aggregationinduced emission of 1-methyl-1,2,3,4,5-pentaphenylsilole. Chem. Commun. 2001, 0, 1740-1741.

(17). Hong Y; Lam JWY; Tang BZ Aggregation-Induced Emission. Chem. Soc. Rev. 2011, 40, 53615388. [PubMed: 21799992]

(18). Mei J; Leung NLC; Kwok RTK; Lam JWY; Tang BZ Aggregation-Induced Emission: Together We Shine, United We Soar. Chem. Rev. 2015, 115, 11718-11940. [PubMed: 26492387]

(19). Singh R; Wu H-Y; Dwivedi AK; Singh A; Lin C-M; Raghunath P; Lin M-C; Wu T-K; Wei K-H; Lin H-CMonomeric and Aggregation Emissions of Tetraphenylethene in a Photo-Switchable Polymer Controlled by Cyclization of Diarylethene and Solvent Conditions. J. Mater. Chem. C 2017, 5, 9952-9962.

(20). Tu Y; Yu Y; Zhou Z; Xie S; Yao B; Guan S; Situ B; Liu Y; Kwok RTK; Lam JWY; Chen S; Huang X; Zeng Z; Tang BZ Specific and Quantitative Detection of Albumin in Biological Fluids by Tetrazolate-Functionalized Water-Soluble AIEgens. ACS Appl. Mater. Interfaces 2019, 11, 29619-29629. [PubMed: 31340641]

(21). Bai J; Tian Y; Liu F; Li X; Shao Y; Lu X; Wang J; Zhu G; Xue B; Liu M; Hu P; He N; Tang Q Octreotide-Conjugated CoreCross-Linked Micelles with pH/Redox Responsivity Loaded with Etoposide for Neuroendocrine Neoplasms Therapy and Bioimaging with Photoquenching Resistance. ACS Appl. Mater. Interfaces 2019, 11, 18111-18122. [PubMed: 31006230] 
(22). Zhan C; Zhang G; Zhang D Zincke's Salt-Substituted Tetraphenylethylenes for Fluorometric Turn-On Detection of Glutathione and Fluorescence Imaging of Cancer Cells. ACS Appl. Mater. Interfaces 2018, 10, 12141-12149. [PubMed: 29116746]

(23). Zhao X; Chen Y; Niu G; Gu D; Wang J; Cao Y; Yin Y; Li X; Ding D; Xi R; Meng M Photostable pH-Sensitive Near-Infrared Aggregation-Induced Emission Luminogen for Long-Term Mitochondrial Tracking. ACS Appl. Mater. Interfaces 2019, 11, 13134-13139. [PubMed: 30901189]

(24). Shi J; Li Y; Li Q; Li Z Enzyme-Responsive Bioprobes Based on the Mechanism of AggregationInduced Emission. ACS Appl. Mater. Interfaces 2018, 10, 12278-12294. [PubMed: 29231713]

(25). Liu Y; Lin FX; Feng Y; Liu X; Wang L; Yu ZQ; Tang BZ Shape-Persistent $\pi$-Conjugated Macrocycles with Aggregation Induced Emission Property: Synthesis, Mechanofluorochromism, and Mercury(II) Detection. ACS Appl. Mater. Interfaces 2019, 11, 34232-34240. [PubMed: 31441635]

(26). Gui S; Huang Y; Zhu Y; Jin Y; Zhao R Biomimetic Sensing System for Tracing Pb2+ Distribution in Living Cells Based on the Metal-Peptide Supramolecular Assembly. ACS Appl. Mater. Interfaces 2019, 11, 5804-5811. [PubMed: 30663882]

(27). La DD; Bhosale SV; Jones LA; Bhosale SV Tetraphenylethylene-Based AIE-Active Probes for Sensing Applications. ACS Appl. Mater. Interfaces 2018, 10, 12189-12216. [PubMed: 29043778]

(28). Cheng HB; Li Z; Huang YD; Liu L; Wu HC PillarareneBased Aggregation-Induced-EmissionActive Supramolecular System for Simultaneous Detection and Removal of Mercury(II) in Water. ACS Appl. Mater. Interfaces 2017, 9, 11889-11894. [PubMed: 28317372]

(29). Wu Z; Mo S; Tan L; Fang B; Su Z; Zhang Y; Yin M Crystallization-Induced Emission Enhancement of a Deep-Blue Luminescence Material with Tunable Mechano- and Thermochromism. Small 2018, 14, 1802524.

(30). Mo S; Meng Q; Wan S; Su Z; Yan H; Tang BZ; Yin M Tunable Mechanoresponsive SelfAssembly of an Amide-Linked Dyad with Dual Sensitivity of Photochromism and Mechanochromism. Adv. Funct. Mater. 2017, 27, 1701210.

(31). Kortekaas L; Browne WR The Evolution of Spiropyran: Fundamentals and Progress of an Extraordinarily Versatile Photochrome. Chem. Soc. Rev. 2019, 48, 3406-3424. [PubMed: 31150035]

(32). Julia-` Lopez A; Ruiz-Molina D; Hernando J; Roscini C. Solid Materials with Tunable Reverse Photochromism. ACS Appl. Mater. Interfaces 2019, 11, 11884-11892. [PubMed: 30816042]

(33). Qiu W; Gurr PA; Qiao GG Color-Switchable Polar Polymeric Materials. ACS Appl. Mater. Interfaces 2019, 11, 29268-29275. [PubMed: 31333022]

(34). Epstein ES; Martinetti L; Kollarigowda RH; Carey-De La Torre O; Moore JS; Ewoldt RH; Braun PV Modulating Noncovalent Cross-links with Molecular Switches. J. Am. Chem. Soc. 2019, 141, 3597-3604. [PubMed: 30661352]

(35). Abdollahi A; Sahandi-Zangabad K; Roghani-Mamaqani H Rewritable Anticounterfeiting Polymer Inks Based on Functionalized Stimuli-Responsive Latex Particles Containing Spiropyran Photoswitches: Reversible Photopatterning and Security Marking. ACS Appl. Mater. Interfaces 2018, 10, 39279-39292. [PubMed: 30379526]

(36). Ji J; Wu T; Zhang Y; Feng F Light-Controlled in Vitro Gene Delivery Using Polymer-Tethered Spiropyran as a Photoswitchable Photosensitizer. ACS Appl. Mater. Interfaces 2019, 11, 1522215232. [PubMed: 30950602]

(37). Ji J; Li X; Wu T; Feng F Spiropyran in Nanoassemblies as a Photosensitizer for Photoswitchable ROS Generation in Living Cells. Chem. Sci. 2018, 9, 5816-5821. [PubMed: 30079193]

(38). Klajn R Spiropyran-based Dynamic Materials. Chem. Soc. Rev. 2014, 43, 148-184. [PubMed: 23979515]

(39). Tsai WK; Lai YS; Tseng PJ; Liao CH; Chan YH Dual Colorimetric and Fluorescent Authentication Based on Semiconducting Polymer Dots for Anticounterfeiting Applications. ACS Appl. Mater. Interfaces 2017, 9, 30918-30924. [PubMed: 28816430] 
(40). Cui L; Zhang H; Zhang G; Zhou Y; Fan L; Shi L; Zhang C; Shuang S; Dong C Substituent Effect on the Acid-Induced Isomerization of Spiropyran Compounds. Spectrochim. Acta, Part A 2018, 202, 13-17.

(41). Jiang T; Wang X; Wang G; Wang Y; Wang K; Xuan X; Chen C; Jiang K; Zhang H Lightactivated "Cycle-reversible Intramolecular Charge Transfer" Fluorescent Brobe: Monitoring of pHi Trace Change Induced by UV Light in Programmed Cell Death. Chem. Commun. 2019, 55, 5279-5282.

(42). Zhang W; Huo F; Yin C Photocontrolled Single-/Dual-Site Alternative Fluorescence Probes Distinguishing Detection of $\mathrm{H}_{2} \mathrm{~S} / \mathrm{SO}_{2}$ in Vivo. Org. Lett. 2019, 21, 5277-5280. [PubMed: 31247742]

(43). Li C; Zhang Y; Hu J; Cheng J; Liu S Reversible Three-State Switching of Multicolor Fluorescence Emission by Multiple Stimuli Modulated FRET Processes within Thermoresponsive Polymeric Micelles. Angew. Chem., Int. Ed. 2010, 49, 5120-5124.

(44). Teunissen AJP; Perez-Medina C; Meijerink A; Mulder WJM Investigating Supramolecular Systems Using Fröster Resonance Energy Transfer. Chem. Soc. Rev. 2018, 47, 7027-7044. [PubMed: 30091770]

(45). Hao M; Sun G; Zuo M; Xu Z; Chen Y; Hu X-Y; Wang L A Supramolecular Artificial LightHarvesting System with Two-Step Sequential Energy Transfer for Photochemical Catalysis. Angew. Chem. 2019, 131, 2-8.

(46). Chen W; Pacheco A; Takano Y; Day JJ; Hanaoka K; Xian M A Single Fluorescent Probe to Visualize Hydrogen Sulfide and Hydrogen Polysulfides with Different Fluorescence Signals. Angew. Chem. 2016, 55, 9993-9996. [PubMed: 27410794]

(47). Li M; Long S; Kang Y; Guo L; Wang J; Fan J; Du J; Peng X De Novo Design of Phototheranostic Sensitizers Based on Structure Inherent Targeting for Enhanced Cancer Ablation. J. Am. Chem. Soc. 2018, 140, 15820-15826. [PubMed: 30380856]

(48). Dwivedi AK; Singh R; Singh A; Wei KH; Wu CY; Lyu PC; Lin HC Novel Water-Soluble Cyclodextrin-Based Conjugated Polymer for Selective Host-Guest Interactions of Cationic Surfactant CTAB and Reverse FRET with Rhodamine B Tagged Adamantyl Guest. Macromolecules 2016, 49, 5587-5598.

(49). Meng LB; Li D; Xiong S; Hu XY; Wang L; Li G FRETcapable Supramolecular Polymers Based on a BODIPY-bridged Pillar[5] arene Dimer with BODIPY Guests for Mimicking the Lightharvesting System of Natural Photosynthesis. Chem. Commun. 2015, 51, 4643-4646.

(50). Zhang M; Yin X; Tian T; Liang Y; Li W; Lan Y; Li J; Zhou M; Ju Y; Li G AIE-induced Fluorescent Vesicles Containing Amphiphilic Binding Pockets and the FRET Triggered by HostGuest Chemistry. Chem. Commun. 2015, 51, 10210-10213.

(51). Guan Q; Li N; Shi L; Yu C; Gao X; Yang J; Guo Y; Li P; Zhu X Aggregation-Induced Emission Fluorophore-Based Molecular Beacon for Differentiating Tumor and Normal Cells by Detecting the Specific and False-Positive Signals. ACS Biomater. Sci. Eng. 2019, 5, 3618-3630.

(52). Xue X; Jin S; Zhang C; Yang K; Huo S; Chen F; Zou G; Liang XJ Probe-Inspired Nano-Prodrug with Dual-Color Fluorogenic Property Reveals Spatiotemporal Drug Release in Living Cells. ACS Nano 2015, 9, 2729-2739. [PubMed: 25688453]

(53). Singh R; Dwivedi AK; Singh A; Lin C-M; Arumugaperumal R; Wei K-H; Lin H-C Exploration of Energy Modulations in Novel RhB-TPE-Based Bichromophoric Materials via Interactions of $\mathrm{Cu}^{2+}$ Ion under Various Semi-aqueous and Micellar Conditions. ACS Appl. Mater. Interfaces 2016, 8, 6751-6762. [PubMed: 26910632]

(54). Keyvan Rad J; Mahdavian AR; Salehi-Mobarakeh H; Abdollahi A FRET Phenomenon in Photoreversible Dual-Color Fluorescent Polymeric Nanoparticles Based on Azocarbazole/ Spiropyran Derivatives. Macromolecules 2016, 49, 141-152.

(55). Zhang J; Fu Y; Han HH; Zang Y; Li J; He XP; Feringa BL; Tian H Remote Light-controlled Intracellular Target Recognition by Photochromic Fuorescent Glycoprobes. Nat. Commun. 2017, 8, 987. [PubMed: 29042558]

(56). Fu Y; Han HH; Zhang J; He XP; Feringa BL; Tian H Photocontrolled Fluorescence "DoubleCheck" Bioimaging Enabled by a Glycoprobe-Protein Hybrid. J. Am. Chem. Soc. 2018, 140, 8671-8674. [PubMed: 29940117] 
(57). Yu Q; Su X; Zhang T; Zhang YM; Li M; Liu Y; Zhang SXA Non-invasive Fluorescence Switch in Polymer Films Based on Spiropyran-Photoacid Modified TPE. J. Mater. Chem. C 2018, 6, 2113-2122.

(58). Wu Z; Pan K; Mo S; Wang B; Zhao X; Yin M Tetraphenylethene-Induced Free Volumes for the Isomerization of Spiropyran toward Multifunctional Materials in the Solid State. ACS Appl. Mater. Interfaces 2018, 10, 30879-30886. [PubMed: 30124289]

(59). Gu F; Zhang C; Ma X Photo-Modulating Multicolor Photoluminescence Including White-Light Emission from a Photochromic Copolymer. Macromol. Rapid Commun. 2019, 40, 1800751.

(60). Fang B; Chu M; Tan L; li P; Hou Y; Shi Y; Zhao YS; Yin M Near-Infrared Microlasers from Self-Assembled Spiropyrane-Based Microsphercial Caps. ACS Appl. Mater. Interfaces 2019, 11, 38226-38231. [PubMed: 31529963]

(61). Li T; He S; Qu J; Wu H; Wu S; Zhao Z; Qin A; Hu R; Tang BZ Thermoresponsive AIE Polymers with Fine-tuned Response Temperature. J. Mater. Chem. C 2016, 4, 2964-2970. 
(a)

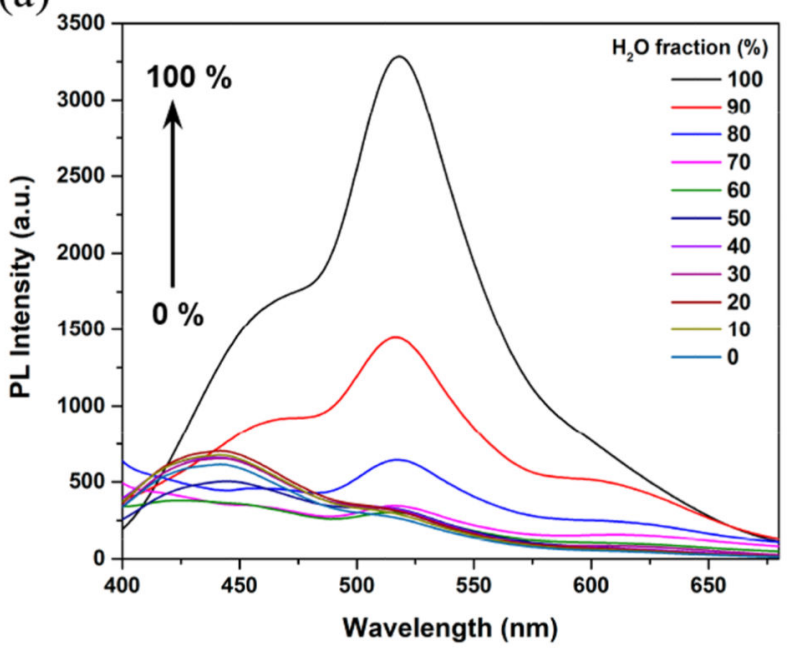

(c)

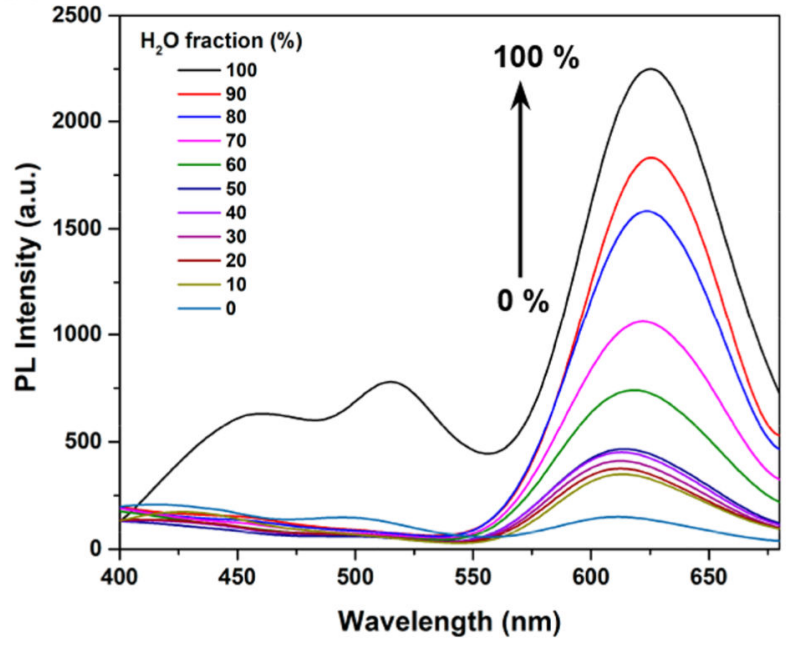

(b)

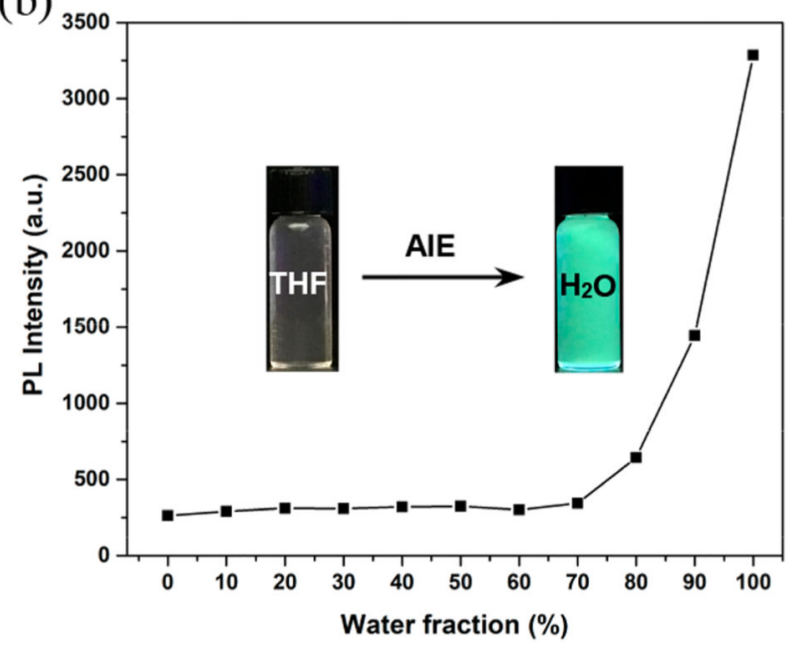

(d)

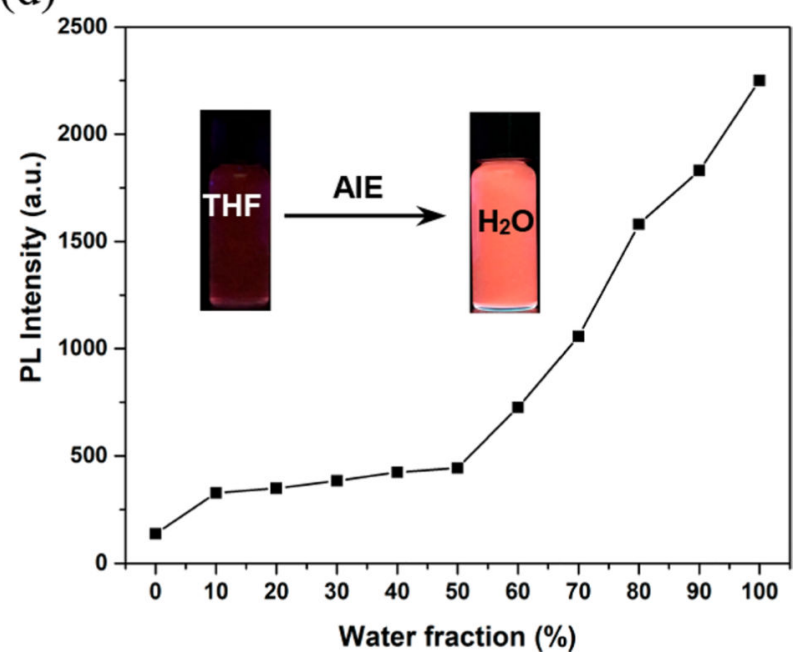

Figure 1.

(a) PL spectra and (b) relative fluorescence intensity at $517 \mathrm{~nm}$ of poly(NIPAM-co-TPESP) and (c) PL spectra and (d) relative fluorescence intensity at $627 \mathrm{~nm}$ of poly(NIPAM-coTPE-MC) with different $\mathrm{H}_{2} \mathrm{O}$ fractions in $\mathrm{THF} / \mathrm{H}_{2} \mathrm{O}$ solutions. Inset: PL photo-images of panel (b) poly(NIPAM-co-TPE-SP) and panel (d) poly(NIPAM-co-TPE-MC) in THF (left) and water (right). Concentration: $1 \mathrm{~g} / \mathrm{L}, \lambda_{\mathrm{ex}}: 365 \mathrm{~nm}$. 
(a)

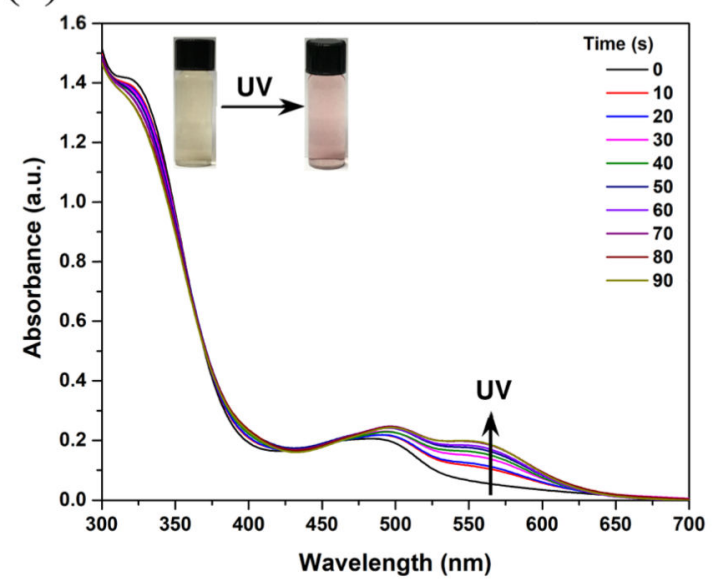

(c)

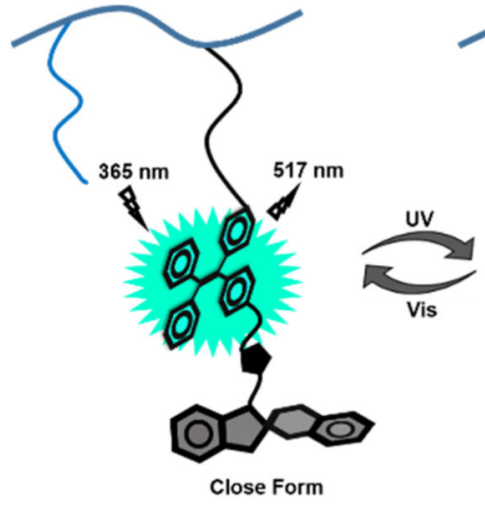

(b)

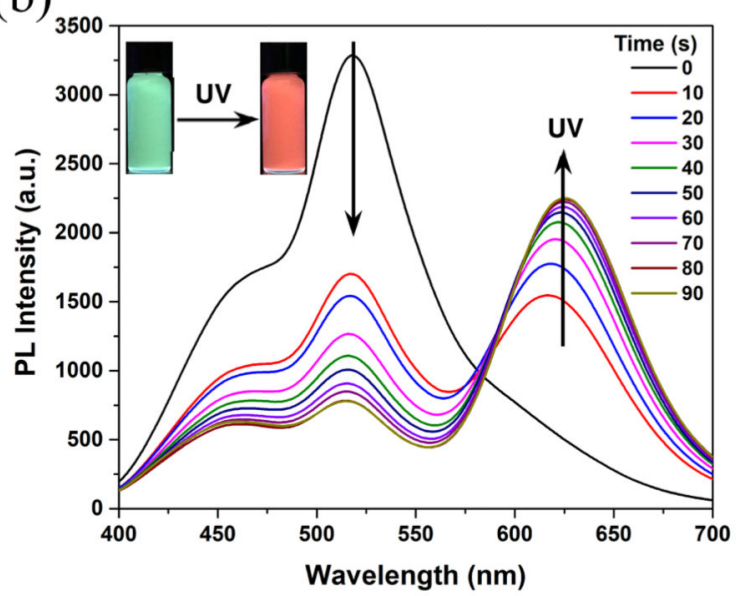

(d)

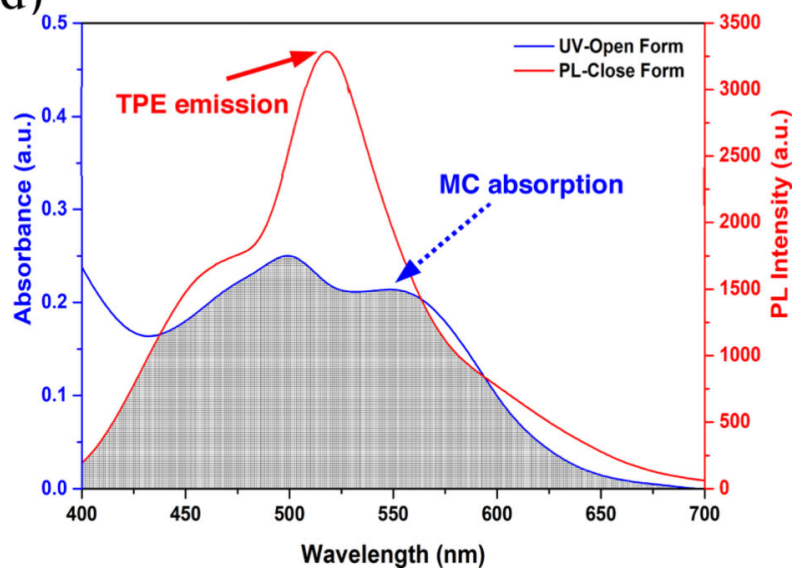

Figure 2.

Time-dependent (a) absorption and (b) PL spectra $\left(\lambda_{\mathrm{ex}}=365 \mathrm{~nm}\right.$ ) of poly(NIPAM-co-TPESP) and poly(NIPAM-co-TPE-MC) (1 g/L) in water upon UV exposure (0-90 s). Insets:

Photo-images of naked-eye observation and photoluminescence color changes. (c)

Schematic illustration of the energy transfer from TPE to MC unit via FRET process after UV exposure and (d) spectral overlap of absorption spectra of poly(NIPAM-coTPE-MC) and emission spectra of poly(NIPAM-co-TPE-SP). 
(a)

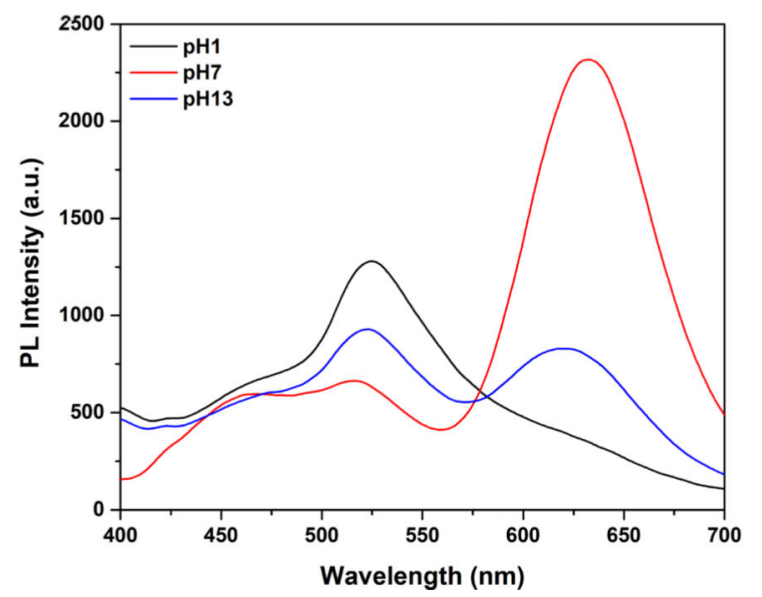

(b)

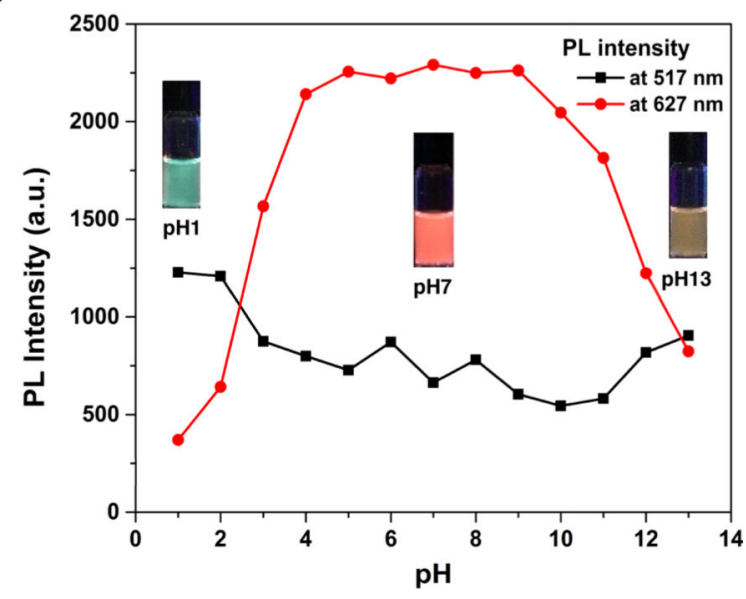

Figure 3.

(a) PL spectra of poly(NIPAM-co-TPE-MC) and (b) relative fluorescence intensities of poly(NIPAM-co-TPE-MC) at 517 and $627 \mathrm{~nm}$ with different $\mathrm{pH}$ values. Insets: PL photoimages of polymer solutions at different $\mathrm{pH}$ values. Concentration: $1 \mathrm{~g} / \mathrm{L}, \lambda_{\mathrm{ex}}: 365 \mathrm{~nm}$. 
(a)

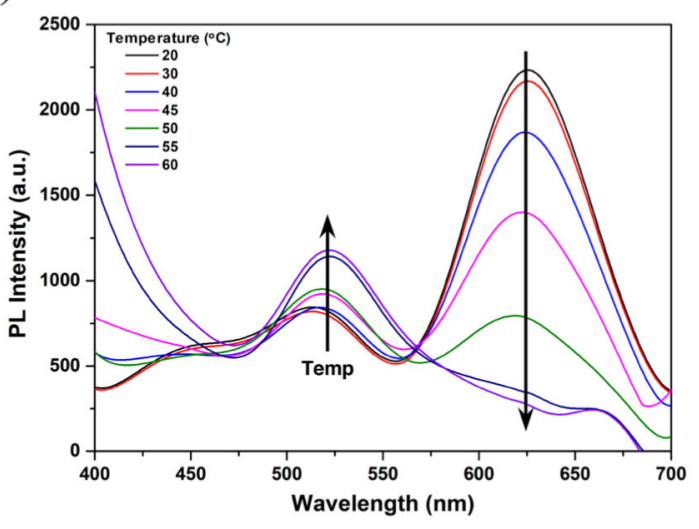

(b)

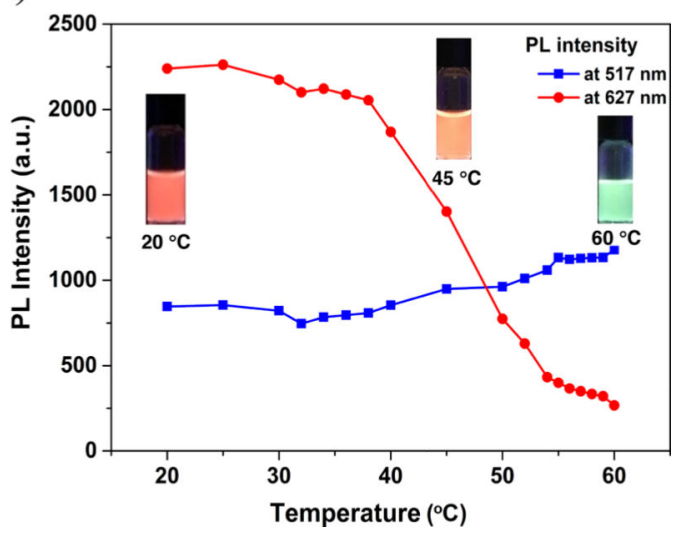

Figure 4.

(a) PL spectra of poly(NIPAM-co-TPE-MC) and (b) relative fluorescence intensities of poly(NIPAM-co-TPE-MC) at 517 and $627 \mathrm{~nm}$ under UV exposure upon heating (20-60

$\left.{ }^{\circ} \mathrm{C}\right)$. Insets: PL photo-images of polymer solutions at different temperatures. Concentration: $1 \mathrm{~g} / \mathrm{L}, \lambda_{\text {ex }}: 365 \mathrm{~nm}$. 
(a)

(c)
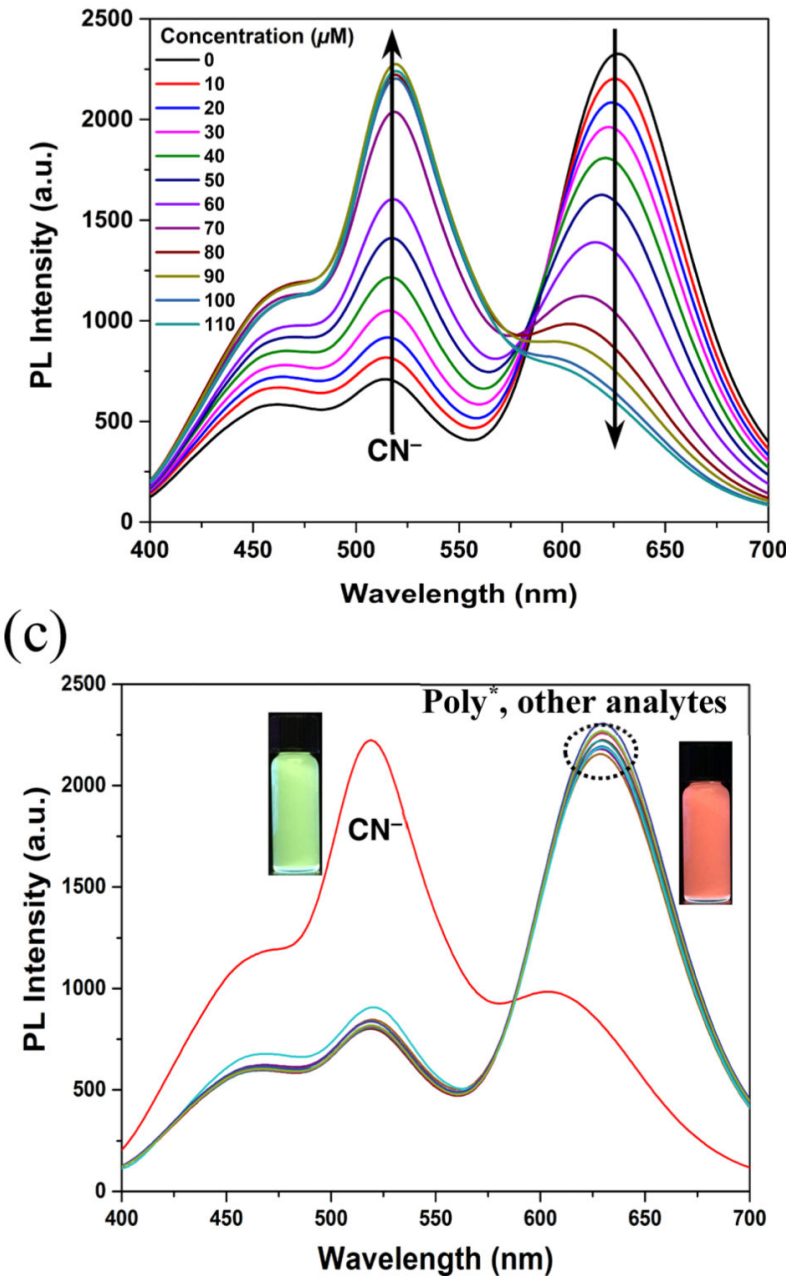

Figure 5. (b)

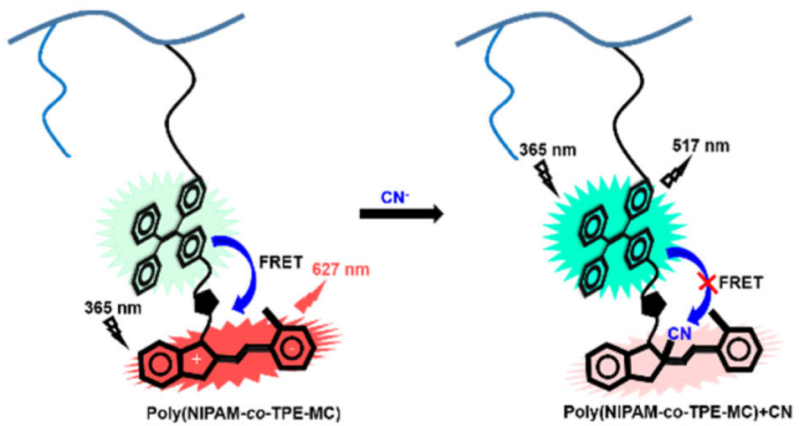

(d)

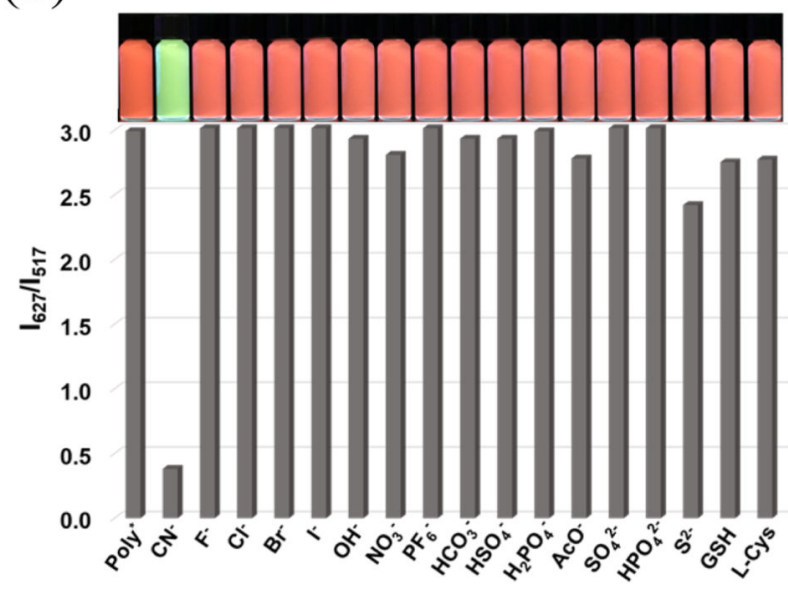

(a) Titration profile change and hypsochromic shift of poly(NIPAM-co-TPE-MC) after addition of different $\mathrm{CN}^{-}$concentrations, (b) proposed schematic illustration of the $\mathrm{CN}^{-}$ detection mechanism, (c) PL spectra (insets: PL photo-images of polymer solution with/ without cyanide ion), and (d) fluorescence intensity ratios response of poly(NIPAM-coTPE-MC) upon addition of various analytes $(200 \mu \mathrm{M})$. Inset: PL photo-images of polymer solutions in the presence of various analytes. Concentration: $1 \mathrm{~g} / \mathrm{L}, \lambda_{\text {ex }}: 365 \mathrm{~nm}$, MOPS buffer solution, *poly(NIPAM-co-TPEMC. 
(a)

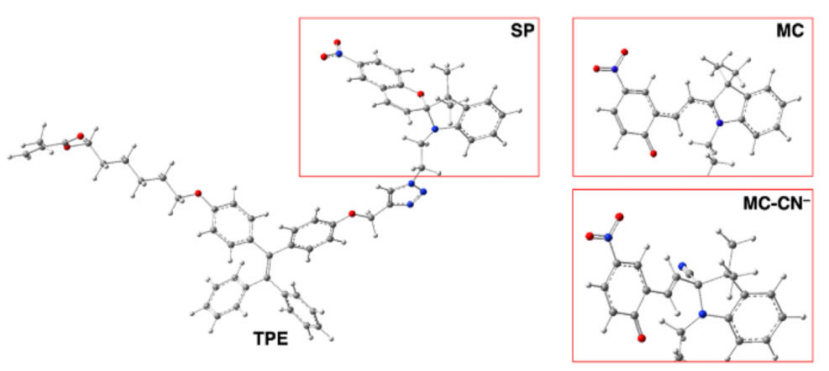

(b)

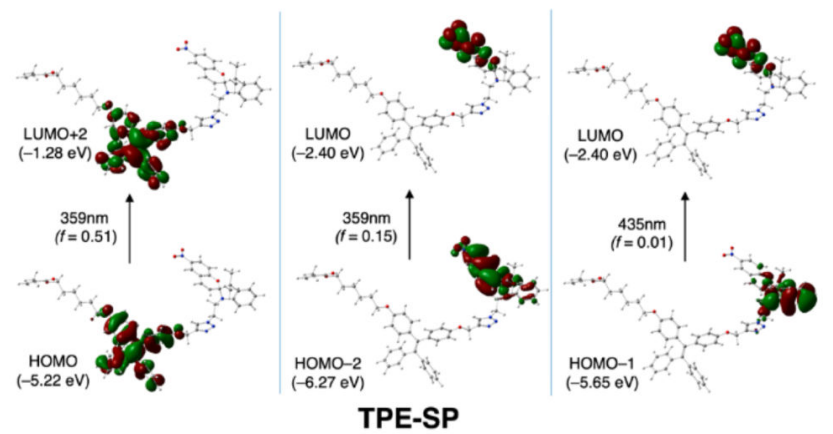

(c)

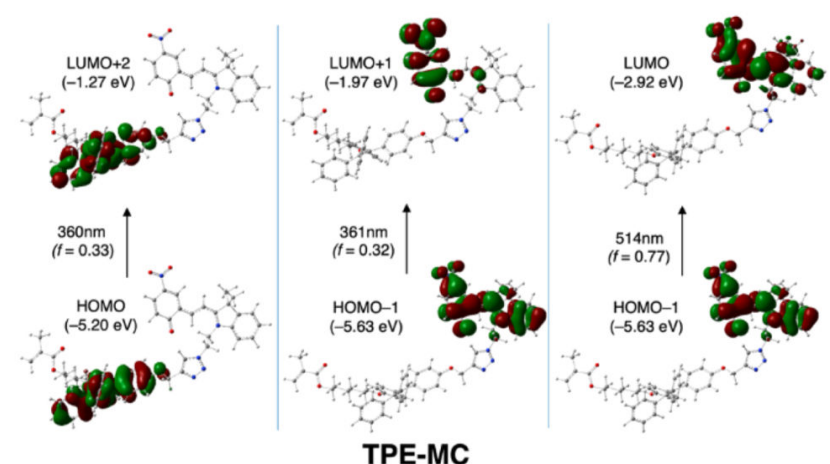

(d)

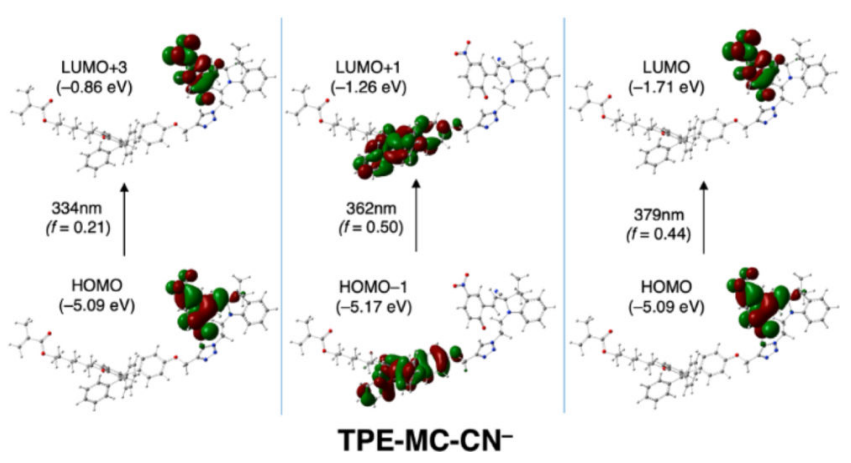

Figure 6.

(a) Optimized structures of TPE-SP, TPE-MC, and TPE-MC-CN ${ }^{-}$at B3LYP/6-31G(d). Only $\mathrm{MC}$ and $\mathrm{MC}-\mathrm{CN}^{-}$fragments of the latter two structures are shown, since the TPE fragment of all three compounds is similar (the optimized coordinates are included in the Supporting Information). Electronic transitions and corresponding molecular orbitals for (b) TPE-SP, (c) TPE-MC, and (d) TPE-MC-CN' ${ }^{-}$. Orbital energies were computed at IEFPCM-B3LYP/6-31G(d). 
(a)

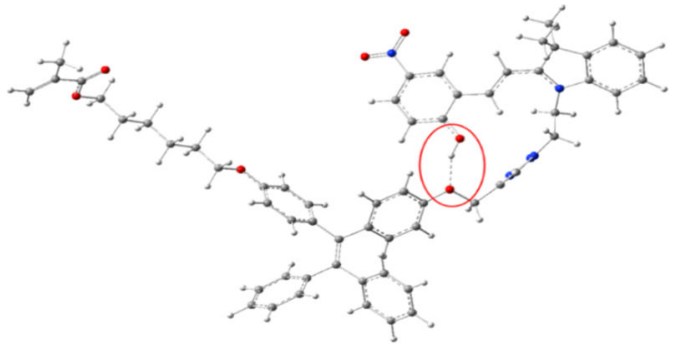

(b)

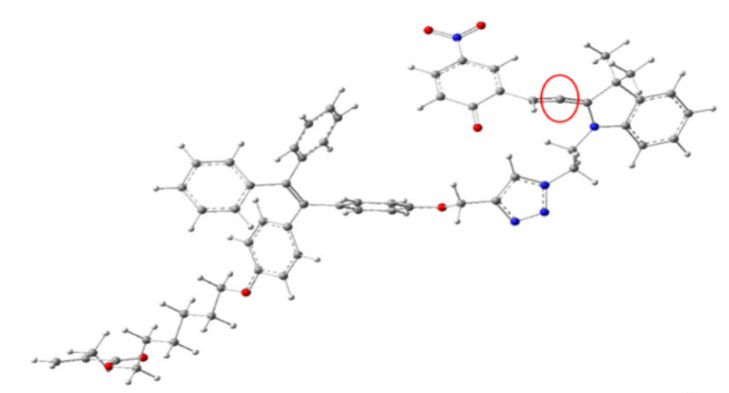

(c)

(d)
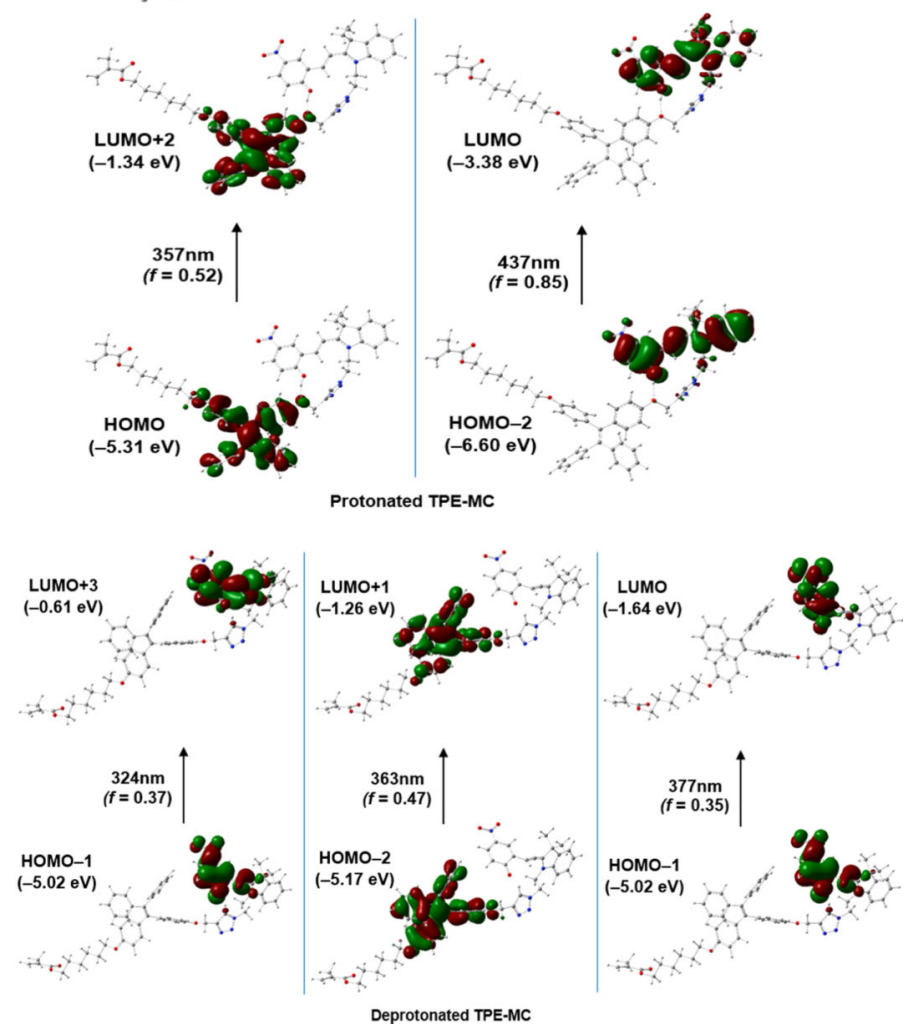

Figure 7.

Optimized structures of (a) protonated and (b) deprotonated TPE-MC at B3LYP/6-31G(d). Protonated and deprotonated positions are circled in red. Molecular orbital diagrams of (c) protonated and (d) deprotonated TPE-MC, with orbital energies computed at IEF-PCMB3LYP/631G(d). 


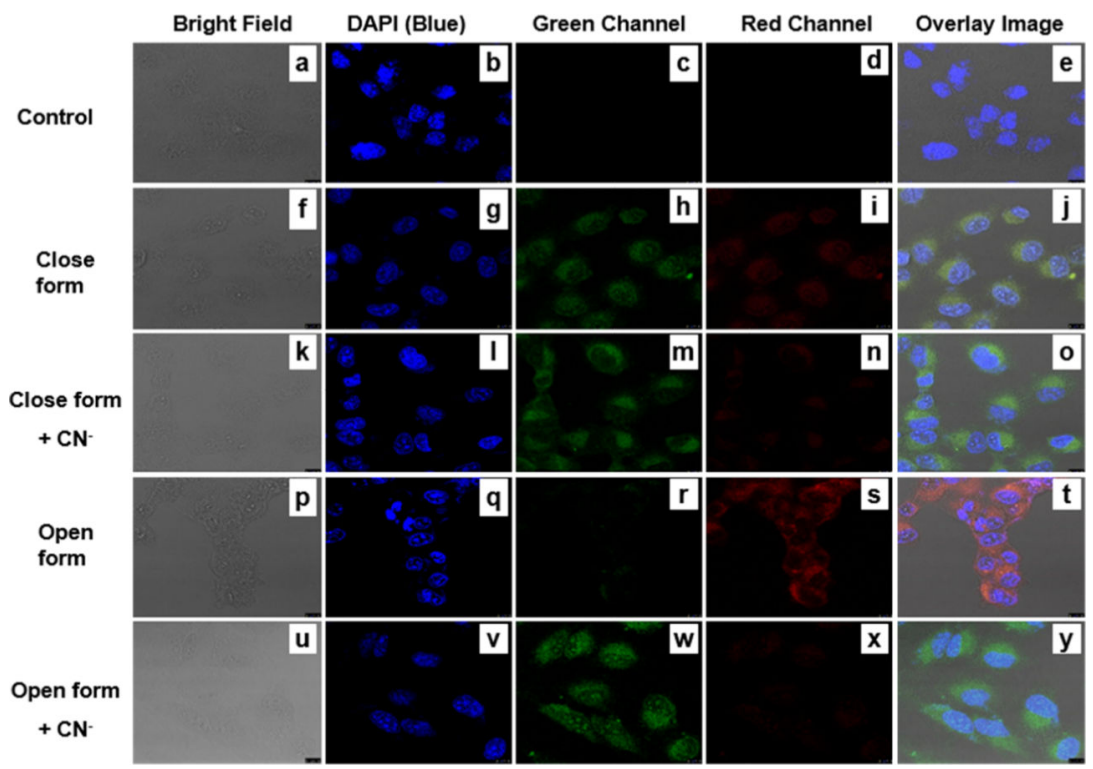

Figure 8.

Confocal fluorescence images of HeLa. (a-e) Control experiments of HeLa. (f-j) Cells were incubated with poly(NIPAM-co-TPE-SP) for $30 \mathrm{~min}$. $(\mathrm{k}-\mathrm{o})$ Cells were treated with poly(NIPAM-co-TPE-SP) for $30 \mathrm{~min}$ followed by incubation with $\mathrm{CN}^{-}$for $30 \mathrm{~min}$. (p-t) Cells were incubated with poly(NIPAM-co-TPE-MC) for $30 \mathrm{~min}$. (u-y) Cells were treated with poly(NIPAM-co-TPE-MC) followed by incubation with $\mathrm{CN}^{-}$for $30 \mathrm{~min}$. The polymeric fluorophores and cyanide concentration $=10 \mu \mathrm{M}$. Green and red emissions were collected at 500-550 and 600-650 nm, respectively. Scale bars $=10 \mu \mathrm{m}, \lambda_{\mathrm{ex}}: 365 \mathrm{~nm}$. 

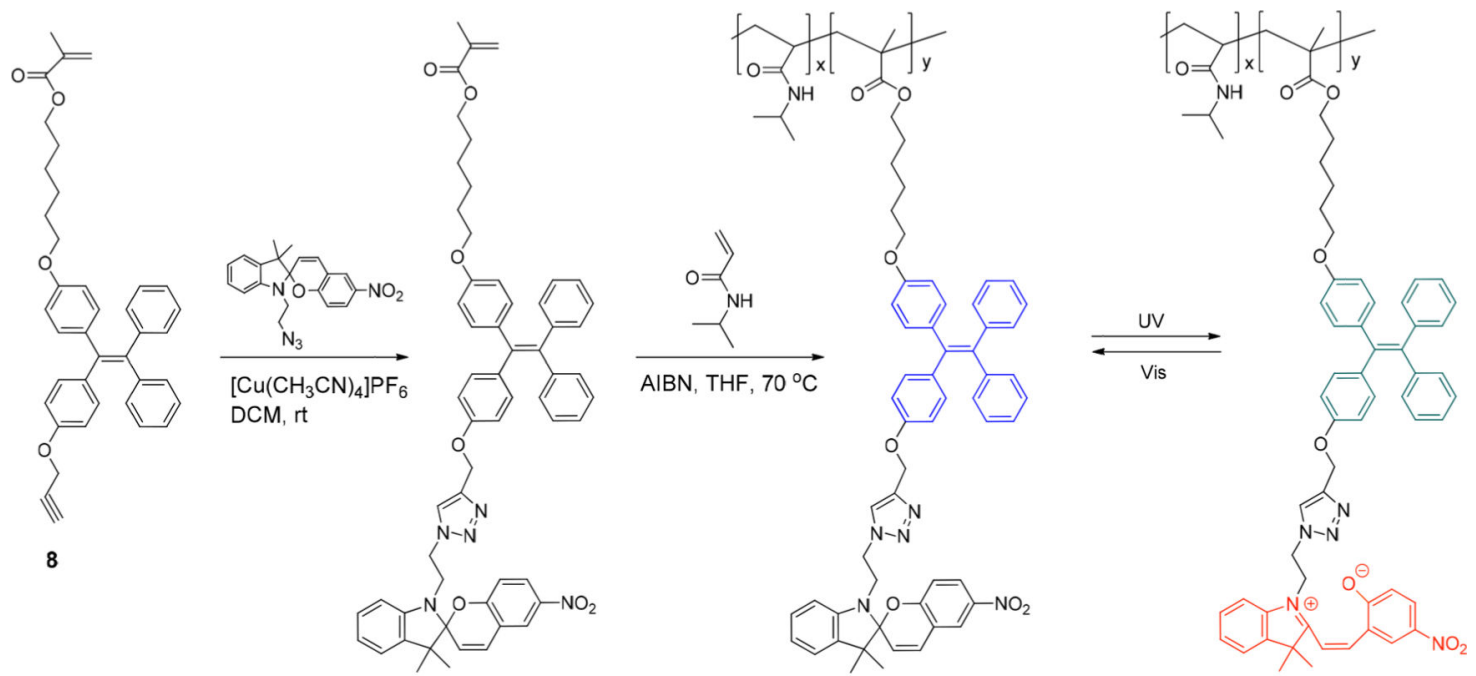

TPE-SP

Poly(NIPAM-co-TPE-SP)

Poly(NIPAM-co-TPE-MC)

Scheme 1.

Synthetic Routes of Monomer TPE-SP and Copolymers Poly(NIPAM-co-TPE-SP) and Poly(NIPAM-co-TPE-MC) 